\title{
Economic and Demographic
} Issues Related to Deployment of the Satellite Power System: (SPS)

October 1978

Prepared for:

U.S. Department of Energy

Office of Energy Research

Satellite Power System Project Office

Under Contract W-31-109-Eng-38

DOE/NASA

Satellite Power System

Concept Development and

Evaluation Program 


\section{NOTICE}

This report was prepared as an account of work sponsored by the United States Government. Neither the United States nor the United States Department of Energy, nor any of their employees, nor any of their contractors, subcontractors, or their employees, makes any warranty, express or implied, or assumes any legal liability or responsibility for the accuracy, completeness or usefulness of any information, apparatus, product or process disclosed, or represents that its use would not infringe privately owned rights.

This report has been reproduced directly from the best available copy.

Available from the National Technical Information Service, U. S. Department of Commerce, Springfield, Virginia 22161.

Price: Paper Copy $\$ 6.00$

Microfiche $\$ 3.00$ 


\section{Economic and Demographic Issues Related to Deployment of the Satellite Power System: (SPS)}

October 1978

Prepared by:

Thomas E. Baldwin

Lawrence G. Hill

Danilo J. Santini

Erik J. Stenehjem

PRC Energy Analysis Company

McLean, Virginia 22102

Prepared for:

U. S. Department of Energy

Office of Energy Research

Satellite Power System Project Office

Washington, D.C. 20545

Under Contract No. W-31-109-Eng-38

\section{DOE/NASA}

Satellite Power System

Concept Development

and

Evaluation Program 
The author acknowledges the following people for their review of the first draft of this White Paper:

Dr. Edward H. Allen

1533 Sumac Drive

Logan, Utah 84321

Mr. Dane L. Mazzitti

Environmental Engineering Division

American Electric Power Service Corp.

P.0. Box 487

Canton, Ohio 44701

Mr. Jack Campbell

U.S. Department of Energy

12 th and Pennsylvania Avenue, N.W.

Room 4324

Washington, D.C. 20461

Dr. Frederick Grygiel

Chief Economist

New Jersey Department of Energy

101 Commerce Street

Newark, New Jersey 07102

Dr. H. Paul Friesema

Center for Urban Affairs

Northwestern University

2040 Sheridan Road

Evanston, I1linois 60201

Mr. Lee Guernsey, Director

River Basin Research Center

159 N. Science Building

Indiana State University

Terre Haute, Indiana 47809

William R. Waters

Department of Economics

DePaut University

25 East Jackson Boulevard

Chicago, Illinois 60604 


\section{Preface}

A series of white papers are being prepared at the request of the Planning Research Company as input to the Societal Assessment of the Satellite Power System (SPS) Concept Development and Evaluation Program sponsored by the United States Department of Energy, Office of Energy Research, SPS Project Office. The objective of the Societal Assessment is to identify and characterize those social, legal, and political ramifications of the SPS technology that might significantly influence its development and to determine strategies that might make the SPS more socially acceptable.

This white paper assesses the impacts of large new energy sources from Satellite Power Systems on the distribution of industry and population in the U.S. and other countries receiving SPS outputs. It was prepared by members of the Economics and Social Sciences Section (ESS) of the Energy and Environmental Systems (EES) Division at Argonne National Laboratory. The effort was led by Dr. Thomas E. Baldwin (EES), with major contributions made by $\mathrm{Dr}$. Danilo J. Santini (EES) and Dr. Lawrence G. Hill (consultant to EES).

Erik J. Stenehjem, Section Leader Economics and Social Sciences Energy \& Environmental Systems Division 
ABSTRACT

EXECUTIVE SUMMARY

1 INTRODUCTION

REFERENCES.

2 INDUSTRIAL LOCATION.

2.1 THEORY

2.1.1 Least Cost Theory . . . . . . . . . . . . . 15

2.1.2 Maximum Profit Theory . . . . . . . . . . . . 16

2.1.3 Theories of Locational Interdependence . . . . . . 17

2.1.4 Integration of Least Cost and Locational

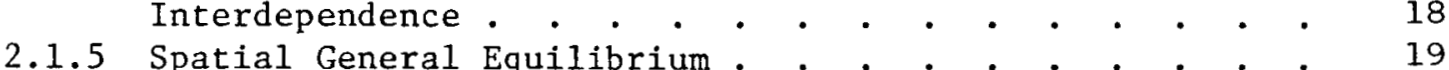

2.1 .6 Recent Contributions . . . . . . . . . . . . . . . 20

2.2 FACTORS AFFECTING INDUSTRIAL LOCATION . • • • • • • • • • • 21

2.2 .1 Primary Factors . . . • . • . . . . . . . . 21

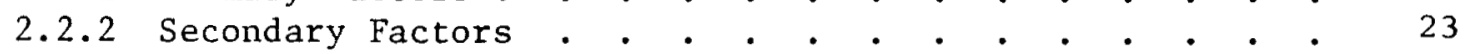

2.3 APPROACHES FOR REGIONAL AND LOCAL ANALYSIS . • • • • • . . 23

2.3.1 Comparative Cost Analysis. . . . . . . . . . . . 24

2.3.2 Input-Output Technique. . . . . . . . . . . . 24

2.3.3 Correlation and Regression Analysis . . . . . . . 25

2.3.4 Export-Base Theory . . . . . . . . . . . . . 25

REFERENCES . • • • • • • • • • • • • • • • • • • • •

3 RELATION OF POPULATION TO INDUSTRIAL LOCATION . . . . . . . . . . 31

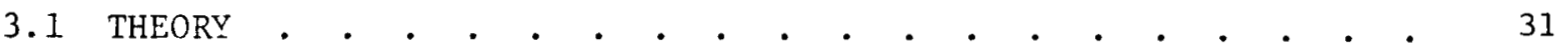

3.1 .1 The Muth Model . . . . . . . . . . . . . 32

3.1 .2 The Santini Model . . . . . . . . . . . . . 32

3.2 ECONOMIC DEVELOPMENT, EXPORT BASE, AND POPULATION CHANGE • • • 33

3.2.1 The Causal Relationship between Export-Base

Employment and Population Change . . . . . . . . 34

3.2.2 An Export Base Model of Employment and 37

3.2.3 Relevance of the Social and Economic Assessment 41

REFERENCES. • • • • • • • • • • • • • • • • • • • 42

4 ANALYSIS AND EVALUATION OF SPS SOCIODEMOGRAPHIC ISSUES . . . . • . 43

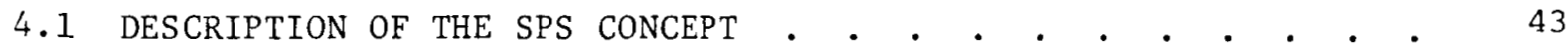

\begin{tabular}{l}
4.2 ISSUES RELATING TO GROUND RECEIVING AND DISTRIBUTION \\
OF SPS ENERGY \\
\hline
\end{tabular}

4.2 .1 Siting . • . . . . . . . . . . . . . . . 44

4.2 .2 Deployment. . . . . . . . . . . . . . . . 47 


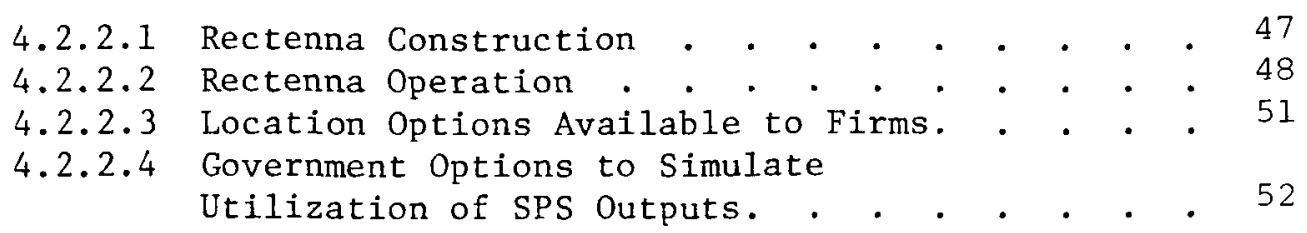

4.3 Public ACCEPTANCE . . . . . . . . . . . . . . . . . . 53

4.3.1 Displacement of Population from Rectenna Sites . . . . 54

4.3.2 Boom Development from Rectenna Construction . . . . . 55

4.3.3 The Centralization of Society. . . . . . . . . . 56

4.4 INTERNATIONAL MOBILITY . . . . . . . . . . . . . . . . . . 57

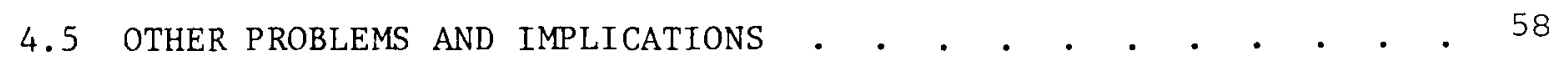

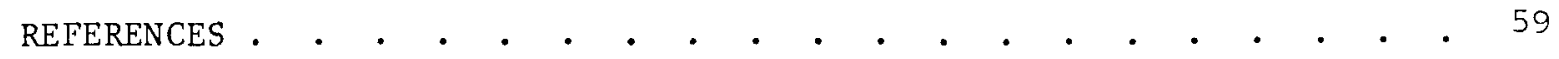

5 FUTURE RESEARCH NEEDS . . . . . . . . . . . . . . . . . . . . 61

5.1 SHORT TERM • . . . . . . . . . . . . . . . . . . . 61

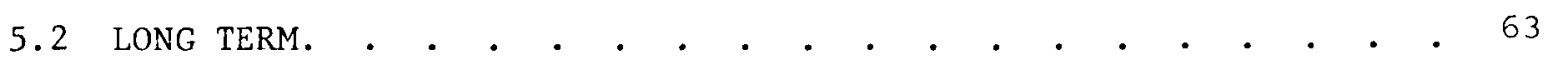

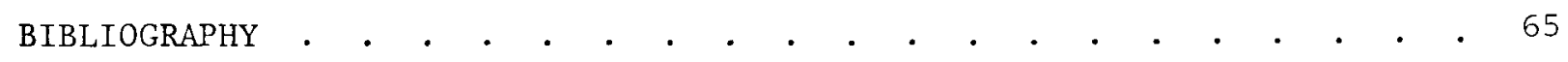

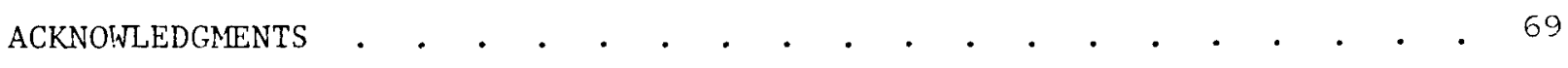




\section{ECONOMIC AND DEMOGRAPHIC ISSUES RELATED TO DEPLOYMENT \\ OF THE SATELLITE POWER SYSTEM: A WHITE PAPER}

by

Thomas E. Baldwin, Lawrence G. Hill, Danilo J. Santini, and Erik J. Stenehjem

\section{ABSTRACT}

Growth in energy consumption has stimulated interest in the exploitation of renewable sources of electric energy. One technology that has been proposed is the Satellite Power System (SPS).

Before committing the U.S. to such a large program, the U.S. Department of Energy (DOE) and the National Aeronautics and Space Administration (NASA) are jointly participating in an SPS Concept Development and Evaluation Program.

This white paper on industrial and population relocation is part of the preliminary evaluation of related socioeconomic issues. The white paper documents the results of four preliminary assessment activities which are as follows:

1. Review existing literature dealing with industrial location, attendant population migration, and the role of electricity availability and pricing as factors influencing economic movements.

2. Identify economic and demographic issues relating to the deployment of SPS.

3. Consideration of the potential significance of these sociodemographic impacts in terms of expected public acceptance by appropriate interest groups.

4. Recommend additional study needs and the most advantageous approaches to these studies.

The conclusion of this preliminary assessment is that FY 1979 study should be concentrated in four assessment areas: rectenna siting strategies, (2) the expected effects of marginal and average cost pricing on industrial and population relocation, (3) the future impact of rectennae siting, and (4) the responsiveness of industry to locate facilities according to the availability and cost of electricity. Long-term research should address the question of whether SPS will contribute to the centralization or decentralization of economic activity and society. 
Consumption of the Earth's fossil and nuclear energy reserves has grown rapidly in the latter half of the 20th century. This growth in consumption, coupled with rapidly increasing prices for these finite resources, has stimulated widespread interest in the exploitation of renewable sources of electric energy. One technology that has been proposed for development is the Satellite Power System (SPS). According to this concept, large satellites in geosynchronous orbit would collect solar energy and convert it to electric energy in space. When beamed to Earth in the form of microwaves, this energy would be collected at receiving antennae (rectennae) and rectified to DC power for distribution through the grid.

Before committing the U.S. to such a large program, the U.S. Department of Energy (DOE) and the National Aeronautics and Space Administration (NASA) are jointly participating in an SPS Concept Development and Evaluation Program. This white paper focuses on the economic and demographic issues of industrial and population relocation around rectenna sites. The white paper is part of the larger preliminary evaluation of socioeconomic issues that is being carried out in FY 1978 to determine research directions for FY 1979 and beyond. To this end, the white paper documents the results of four preliminary assessment activities which are as follows:

1. Review existing literature dealing with industrial location, attendant population migration, and the role of electricity availability and pricing as factors influencing economic movements.

2. Identify economic and demographic issues relating to the deployment of SPS.

3. Consider the potential significance of these economic and demographic impacts in terms of expected public acceptance by appropriate interest groups.

4. Recommend additional study needs and the most advantageous approaches to these studies.

Section 1 provides an overview of the SPS concept and introduces the concerns of this white paper. Sections 2 and 3 review the rather extensive literatures dealing with industrial location and the relationship between industrial moves and population migration. Except for some broad generalizations, there is no information about industrial relocation or population migration 
consequences in the SPS 11terature. Therefore, these sections review knowledge about Industrial location and population migration that has accumulated independent of the SPS 1ssue. Section 2 traces the development of industrial location theory and places in perspective the primary and secondary factors that have been shown by empirical research to influence the distribution of industrial activity. Section 2 concludes with a review and assessment of approaches to locational analysis that can be applied to the study of industrial location as it may be affected by SPS. Export-base theory is evidenced to provide a strong foundation for estimating the types and levels of basic economic activity (e.g., manufacturing) that may be attracted toward the SPS electric rectifying sites. It is concluded that, from these estimates of basic industrial attraction, one can develop forecasts of the employment and population changes attendant to relocations of manufacturing using additional methods. However, in order to apply these additional methods, the causal relationship between economic change and population migration must be understood. Section 3 reviews the literature that has examined this relationship and assesses the two schools of theory that have emerged. Export-base theorists have held that population follows movements of economic activity and employment; whereas another school of theorists have held that change in economic activity and employment follows population movements. The most important differences between these theories are examined in Sec. 3 and the findings of supporting studies are assessed. Based on this assessment, it is concluded that export-base provides the more valid theory upon which to build a methodology for estimating changes in regional employment and population resulting from the development of electric generating capacity. Section 3 also describes a computerized export-base methodology that has been developed at Argonne National Laboratory (ANL) for this purpose.

Section 4 focuses on the economic and demographic problems and implications particular to SPS rectenna siting that need further study using the approach set forth in Sec. 3. After a brief description of the SPS concept, and a short statement of justification for concentration on the rectenna element of the system, Sec. 4 examines the pre-deployment implications for population displacement and the post-deployment impacts of industrial and population relocation. This section also deals, albeit briefly, with the issues of public acceptance and international moves as they relate to rectenna siting in the U.S. The major conclusions of Sec. 4 are that rectennae siting and the pricing 
of electric outputs will be the prime determinants of the impact that SPS may have on the future distribution of economic activity and society. First, any SPS-effected relocation of industry and population will depend upon where the large microwave receiving and electric distribution facilities that are required for the envisioned 5-GW satellites are sited. Using the existing U.S. standard for microwave radiation exposure $\left(10 \mathrm{~mW} / \mathrm{cm}^{2}\right)$, each elliptical rectenna would cover approximately $132 \mathrm{~km}^{2}$. Full deployment of a 60-satellite (300-GW capacity) system, with a separate rectenna for each satellite, would therefore require approximately $7900 \mathrm{~km}^{2}$, or about $0.09 \%$ of the total U.S. 1and area devoted to rectenna sites. Two preliminary siting studies indicate that the rectennae would need to be located in rural areas and one of these studies indicates that rectennae may need to be clustered in undeveloped regions to optimize the avoidance of densely populated areas, with the availability of relatively cheap land and proximity to load centers or utility tie points. Second, the cost of transmitting the generated electricity is a critical consideration. By the time SPS becomes operational, it may not be economically feasible to transmit the power over long distances from rural rectennae sites through the grid to existing manufacturing centers. If this is the case, the total cost of rectennae siting will include redistributing a portion of the load and the conversion of existing land-uses, as well as construction of the rectenna consisting of land acquisition, preparation of the site, transport of materials, and assembly of the elements. On the other hand, it may be feasible to transmit electricity over long distances, but this will probably require substantial renovation of the existing distribution system in addition to annual operating costs and design, development, test, and evaluation (DDT\&E) costs of SPS. There are several pricing strategies that can be applied to cover the costs of developing SPS electricity. They include: average cost pricing, capacity-only pricing, peak and off-peak pricing, energy-only pricing, and marginal cost pricing. Average and marginal cost pricing are particularly important in considering industrial location incentives that may develop.

Based on the review of literature in Secs. 2 and 3 , and the identification in Sec. 4 of rectennae siting and electricity pricing as the prime determinants of effects SPS may have on industrial and population relocation, Sec. 5 specifies short-term assessments that should be undertaken in FY 1979, as well as some long-term research needs for FY 1980 and beyond. The shortterm assessments are needed to first build an arsenal of tools and understanding 
that can serve as a foundation for the more refined assessments that will be required as evaluation of the SPS concept proceeds. Long-term research should be aimed at developing accurate predictions of whether SPS will contribute to the centralization or decentralization of society. However, before investigators can seriously tackle this larger question, the more fundamental issues must be examined. These would include the consideration of maximizing economic and demographic benefit from rectennae siting; the relationships between electricity prices, industrial moves, and population migration; potential socioeconomic impact from these moves; and the future locational responsiveness of industry based on the availability and cost of electricity. These issues are interrelated and the study of each should build from assessments of the most fundamental issues. For these reasons, the short-term research needs have been characterized and prioritized as follows:

- Rectenna siting assessment (two possible approaches)

- Search for sites (i.e., counties) that maximize the economic/demographic benefits of SPS.

- Evaluate the economic/demographic viability of sites identified by others.

- Assess the expected effects of marginal and average cost pricing on industrial moves to rectenna-bearing regions. This assessment would include some sensitivity analysis.

- Ex ante assessment of economic/demographic impact of rectenna siting. This assessment would examine the following phases of SPS development:

- Rectenna construction and secondary growth

- Initial industrial relocation and secondary growth

- Attraction of related industrial economic activity and their secondary effects

- Assess the responsiveness of industry to relocate facilities based on the availability and cost of electric power. This assessment would include:

- Identification of electric-intensive industries and processes

- Consideration of projected regional generating capacities that may influence future shifts in the spatial location of industry

- Price comparisons of SPS electricity with other forms of generation.

- Identification of industry-specific resource needs and other incentives that may influence relocation decisions such as water availability; transportation or labor requirements; market locations; and government policies at the local, state, and federal levels 
These short-term assessments will contribute information about the industrial markets that SPS can be expected to serve. Anticipation of these markets is essential to the use of our export-base approach for projecting economic and demographic changes from SPS deployment.

When understanding developed from the short-term assessments is avai1able, the question of whether SPS will contribute to the centralization or decentralization of American economy and society can be examined more critically in the long-term. 


\section{INTRODUCTION - STATEMENT OF ISSUE AND PURPOSE OF THIS WHITE PAPER}

Consumption of the Earth's fossil and nuclear energy reserves has grown rapidly in the latter half of the 20 th century. This growth in consumption, coupled with rapidly increasing prices for these finite resources, has stimulated widespread interest in the exploitation of renewable sources of electric energy. One technology that has been proposed for development is the Satellite Power System (SPS). According to this concept, large satellites in geosynchronous orbit would collect solar energy and convert it to electric energy in space. When beamed to Earth in the form of microwaves, this energy would be collected at receiving antennae and rectified to DC power for distribution through the grid. The SPS concept involves a complex program that encompasses development of the following elements: the satellite power station, space transportation systems to provide for construction of the satellite stations, microwave power transmission, and ground receiving and distribution.

The Baseline System Concept developed by the National Aeronautics and Space Administration (NASA) calls for a scenario of implementing two 5-GN SPS systems per year (10 GW) for 30 years, beginning with an initial operational date of the year 2000 for the first unit. Attainment of this scenario would result in an SPS generating capacity of 300-GW in the year 2030 and require capital investment of $\$ 718$ to $\$ 793$ billion in 1977 dollars. ${ }^{1}$ Based on present estimates, such an SPS system would contribute a significant portion of the total U.S. installed electrical capacity by $2030 .^{2}$

Before committing the U.S. to such a large program, the U.S. Department of Energy (DOE) and NASA are jointly participating in an SPS Concept Development and Evaluation Program. This evaluation program includes four functional study areas: (1) systems definition, (2) evaluation of environmental, health, and safety factors, (3) related socioeconomic issues, and (4) comparative assessment of alternative energy systems. Preliminary program recommendations are to be made by May, 1979, and final program recommendations will be presented in June, 1980. ${ }^{1}$

This white paper on industrial and population relocation is part of the preliminary evaluation of related socioeconomic issues that is being carried out in FY 1978 to determine research directions for FY 1979. Overall, the socioeconomic evaluation comprises twelve white papers that assess different 
aspects of the impacts that SPS is likely to have on national and international society, exclusive of environmental, health, and safety issues. ${ }^{3}$ This paper focuses on the economic and demographic impacts that operating a large SPS system may have on industrial location and population distribution at the local, regional, and national levels in the U.S. Issues tangential to this primary focus are: public acceptance of the SPS concept, the centralization or decentralization of American society that may result from its deployment and international movements of industry and/or population. These latter issues are accorded limited attention because they are the primary concerns of other white papers. The purpose of this preliminary assessment is to survey existing literature, delineate important impact considerations, and establish a basis for further work. To this end, the white paper documents the results of four preliminary assessment activities which are as follows:

1. Review existing literature dealing with industrial location, attendant population migration, and the role of electricity availability and pricing as factors influencing economic movements.

2. Identify economic and demographic issues relating to the deployment of SPS.

3. Consideration of the potential significance of these sociodemographic impacts in terms of expected public acceptance by appropriate interest groups.

4. Recommend additional study needs and the most advantageous approaches to these studies.

For purposes of the Concept Development and Evaluation Program, elements of the SPS concept have been grouped in several ways; but one aggregation that has proven most helpful in formulating this paper is set forth by NASA. ${ }^{2}$ In that report, the major SPS elements are grouped as follows:

\section{Satellite Power Station}

This element encompasses the power conversion options being studied. In addition to the photovoltaic and thermal solar energy conversion options, contractor studies are being performed on nuclear energy conversion systems. Each conversion option uses a rather similar microwave power conversion and transmission system as part of the satellite power station.

Ground Receiving and Distribution Site

This element includes the receiving antenna for the microwave beam, the utility interface with the related electric ground distribution system, the safety system related to microwave exposure protection and to the safety of maintenance and service activities, and the maintenance and service system. 
Manufacturing, Construction, and Maintenance Operations

This element includes ground and orbital operations and their respective systems that support the required manufacturing, construction, assembly, and maintenance activities. A special operations management activity ties together equipment and manned operations and transportation and logistics requirements.

\section{Space Transportation}

This element consists of five transportation systems necessary to provide operational satellite power systems: the heavy lift launch vehicle (HLLV), the personnel launch vehicle (PLV), the cargo orbital transfer vehicle (COTV) system, the personnel orbital transfer vehicle (POTV) system, and local space transportation vehicle (LSTV) systems.

This paper specifically deals with the influence that the availability and cost of electricity have on the spatial location of industry and population. Accordingly, we are primarily concerned with the relocation of industry and population to regions containing SPS ground receiving and distribution (rectennae) sites that may be operating to supply a significant portion of the U.S. electricity demand early in the next century. Two fundamental issues are emphasized in the preliminary assessment of impacts resulting from these terrestrial operations: (1) the displacement of population from large areas of low density land where the rectennae will be sited, and (2) the redistribution of industry and population that may result based on the availability and cost of SPS generated electricity.

Although estimates vary slightly, the typical 5-GW rectenna would contain on the order of $10^{12}$ dipole elements which, when assembled into an elliptical array, would cover an active area of approximately $78.5 \mathrm{~km}^{2}(30.3$ $\mathrm{mi}^{2}$ or about 19,400 acres) and require a total land area of $132 \mathrm{~km}^{2}\left(51.0 \mathrm{mi}^{2}\right.$ or about 32,600 acres). ${ }^{1}$ Based on the current U.S. standard for human exposure to microwaves $\left(10 \mathrm{~mW} / \mathrm{cm}^{2}\right)$, no safety zone would be required around the rectenna site. ${ }^{2} *$ Even in the absence of a safety zone, full deployment of a 60-satellite system with a separate rectenna for each orbiting station would require a substantial investment of 1and. The two preliminary siting studies that have been undertaken to date ${ }^{4,5}$ emphasize low population density as site selection criterion

*If the U.S. standard for exposure to microwave radiation were lowered to 0.1 $\mathrm{mW} / \mathrm{cm}^{2}$, a safety zone would be needed. Addition of this buffer would increase the area covered by each rectenna site to approximately $100 \mathrm{mi}^{2}(64,000$ acres $) .^{2}$ 
to minimize the displacement of population. These land and population considerations will cause the rectennae to be sited either in rural areas of urbanized regions or in rural regions of the U.S., and the displaced population will have to be redistributed among other geographic locations and sectors of the economy. Another, and in many respects, more important consideration is the proximity of the rectennae to major loads or utility tie points. Assuming that the utility interfaces are within 150 miles of the receiving site, a transmission efficiency of $98 \%$ can be expected. ${ }^{2}$ Since the price of SPS electricity will be affected by transmission efficiency, there may be incentives for electric-intensive industries to move to regions containing rectennae, and this would, in turn, improve the local tax base.* Furthermore, to the degree that these industries need labor, population can be expected to move with the jobs that would be relocated. These are, in elementary terms, the major economic and demographic issues that are addressed in this white paper.

Except for some broad generalizations, there is no information about industrial relocation or population migration consequences in the existing SPS literature. Therefore, this preliminary assessment is based upon literature drawn from the fields of economics and demography and professional judgments formulated by these authors based on technical descriptions of the SPS concept. Sections 2 and 3 of this paper review the rather extensive literatures dealing with industrial location and population migration. These sections relate migration to past movements of industry that have occurred independent of the SPS issue. Section 2 summarizes the historical development of industrial location theory and places in perspective factors that have been shown by empirical research to influence the distribution of industrial activity. Section 2 concludes with a review and assessment of approaches to locational analysis that can be applied to the study of industrial location as it may be affected by SPS. Section 3 reviews literature developed from the two major schools of theory dealing with the relationship between economic development (i.e., industrial location) and population migration and, based on the foregoing assessment of approaches to locational analysis, we recommend use of an export-base approach to study the regional economic and demographic consequences of SPS rectenna siting. Building on this background, Sec. 3 also

* Of course, any improvement of local tax bases due to industrial relocation would be accompanied by a concomitant, although more diffuse, decaying of some other local tax bases. 
discusses how the export-base approach can be used to study the interactions among (1) the magnitude of economic development (i.e., the creation of jobs), (2) the resulting spatial location of workers and their dependents, and (3) subsequent demands for services. Section 4 specifies the economic and demographic problems and implications particular to SPS rectenna siting that need more detailed examination using the approach set forth in the previous section. After a brief description of the SPS concept and a statement of justification for concentration on the rectenna element of SPS, Sec. 4 focuses on the predeployment impact of population displacement and the post-deployment impact of industrial and population relocation. Section 4 also deals with the issues of public acceptance and international mobility as they relate to rectennae siting in the U.S. Based on the review of literature and identification of the economic and demographic implications of SPS, Sec. 5 identifies short-term assessment work that should be undertaken in FY 1979 and some long-term basic research topics that need to be addressed in FY 1980 and beyond. 


\section{SECTION 1 REFERENCES}

1. Solar Power Satellite Baseline Review by MSFC-JSC, Preliminary (July 13, 1978).

2. NASA, George C. Marshal1 Space Flight Center, Satezlite Power System Engineering and Economic Analysis -- Summary, NASA TM X-73344 (Nov. 15, 1976).

3. Bloomquist, Charles E., Draft Recommendations for a Detailed Program to Assess the Societal Impacts of a Satelzite Power System, Planning Research Corporation (May 4, 1978).

4. Eberhardt, Anne W., Candidate Locations for SPS Rectifying Antennas, NASA TM-78146 (Nov. 1977).

5. Arthur D. Little, Inc., Rectenna Siting Requirements, unpublished information. 
A key socioeconomic effect of the SPS system is the likelihood of industry to locate near the rectennae. This section reviews pertinent industrial location theories, factors affecting industrial location, and approaches for locational analysis. The reason for examining the literature on industrial location analysis is to gain understanding about how industry may be redistributed based on the availability and cost of electricity around rectennae sites. This understanding is critical to estimating changes in regional as well as local employment and population levels that may occur subsequent to SPS deployment.

\subsection{THEORY}

This survey of economists' contributions to industrial location theory is a highly selective summary of important theories. We will summarize five generally recognized categories of industrial location theory. These are: least cost theory, maximum profit theory, theories of locational interdependence, integration of least cost and locational interdependence, and spatial general equilibrium theory.' A brief discussion of each of these categories is a necessary prelude to choosing a method of analysis for assessing industrial and demographic location around an SPS rectenna site. Recent contributions to industrial location theory will be summarized separately.

\subsubsection{Least Cost Theory}

Johann $H$. von Thunen was among the earliest economists interested in locating theory.' He was concerned with the optimum location for agricultural crops in relation to a city. Although this theory was formulated to determine the least cost areas for agricultural crops, it provided a theoretical framework for later industrial location theory by utilizing the two variables of land rents and transportation costs. Alfred Weber developed a more comprehensive least cost theory many years later. ' Weber postulated that if weight and distance are the only determining factors, transportation costs will attract industrial production to those places where the fewest ton-miles originate during the entire process of production and distribution because transportation costs will be lowest at those points. Labor costs are the 
second factor that Weber considered vital in the location of manufacturing. The basis of Weber's law of labor orientation is related to the idea that every point of lower labor costs constitutes a center of attraction that tends to draw industry from the point of minimal transport cost. In Weberian theory, besides the costs of transportation and labor that affect the regional location of industry, there are other factors, known as agglomeration factors, that contribute to the local distribution of industry. Weber defines an agglomeration factor as an "advantage" in production or marketing costs at a specific place. In contrast, a deglomerative factor is one that lowers production costs because of the decentralization of production. Edgar M. Hoover has built upon these contributions to least cost location theory. ${ }^{2}$ His main contribution lies not in theoretical originality, but in his penetrating discussions of the influence of Weberian locational factors. He stresses the fact that the cost of transferring outputs does not increase proportionately with distance. Where Weber's analysis often indicated the optimum location to be between the points of supply and demand, Hoover's accounting for terminal (or transfer) costs explained why industries are often found at the point of supply or demand. Hoover's analysis of the agglomerating and deglomerating forces is also much more penetrating than Weber's. Included in agglomeration are such advantages as better transfer services, a broader, more flexible labor market, more advanced banking facilities, better police protection, and lower insurance costs and utility rates. In addition, by agglomerating and localizing, Hoover postulates that firms specialize to a greater degree. Thus, certain operations and services that a plant in a less industrialized area would have to do for itself can be economically contracted out as the industrial infrastructure of an area develops.

Least cost analysis and agglomeration characteristics are important concepts to be considered in the socioeconomic assessment of SPS. The SPS system could provide cheap and/or highly dependable electric power as an incentive for relocation. This possibility will be explored later in this white paper.

\subsubsection{Maximum Profit Theory}

August Lösche developed the maximum profit theory of industrial location. This theory is based on conditions of monopolistic competition, as advocated by Weber's least cost theory. ${ }^{4}$ The profit maximizing theory of industrial location recognizes that the site of an industrial enterprise rests 
not only on objective facts of cost, but also on subjective considerations about potential markets. Consequently, two entrepreneurs may choose two different locations under exactly identical external conditions. The range of sites depends on the size of the possible profits. A factory may be established at a place where revenue is greatest rather than where cost is smallest. Lösche also refined this concept. The plant may not be established at the place of largest sales, but where one of the sales' components, such as quantity or price, prevails. Orientation to quantity reflects the number of buyers, whereas orientation to prices recognizes the importance of purchasing power. The former favors populous areas while the latter favors prosperous areas. Lösche assumed a single hexagonal market area surrounding each center of production. The optimum location changes with each price change, which directly affects demand. Thus, when variability in market demand is considered, as Lösche indicated, the least-cost theory -- which is based on cost of production -- loses validity. It then becomes meaningless to attempt to locate at the point of lowest cost. As a result, there must be an attempt to find the largest market area that will then provide the greatest profit. This is the central theme of the maximum profit theory. ${ }^{1}$ If Lösche's theory is correct, the SPS system may not attract industry to its immediate vicinity since preliminary siting studies indicate the rectennae are to be located in sparsely populated areas where markets are limited. This thought will be explored later.

\subsubsection{Theories of Locational Interdependence}

To overcome some of the weaknesses in traditional least cost theory, the "locational interdependence" or "market area" school of thought came to be developed. This school includes the works of economists who, like Lösche, are interested in the theory of imperfect or monopolistic competition. They include: Hotelling, ${ }^{9}$ Chamberlin, ${ }^{10}$ Lerner and Singer, ${ }^{11}$ Smithies, ${ }^{12}$ and Ackley. ${ }^{13}$ This approach generally assumes that all firms have identical production costs and sell to a spatially distributed market. The delivered price to consumers varies with the cost of overcoming distance from the factory. Each seller, in choosing his location, seeks to control the largest possible market area, the positions and extent of which will be influenced by consumer behavior and by the locational decisions of other firms. The manufacturer exercises monopoly control over that section of the market that he can supply at a lower price than his competitors. The spatial pattern of plant location and market areas is thus 
a product of variations from place to place in demand and of the locational interdependence of firms. ${ }^{5}$ For those industries to which this school of thought applies, little relocation of industry to rectennae-bearing regions will occur. Future research should identify specific industries to which the particular theories apply and then to select those theories as a basis for the further study of rectenna siting impacts.

\subsubsection{Integration of Least-Cost and Locational Interdependence}

Melvin Greenhut has provided the most logical theory in attempting to integrate the least-cost and locational interdependence theories. Of particular value is Greenhut's discussion of the location factors. He lists these as transportation, processing costs, the demand factor, and what he describes as "cost-reducing" and "revenue-increasing" factors. Generally, he notes, one factor is of particular importance, with secondary factors coming into play when the governing factor gives alternative sites. Transportation costs become the most important factor in the localization of manufacturing when processing costs, market demand, and personal factors are held constant. When transportation costs dominate, they become an important influence in the decentralization of an industry. Processing costs may dominate in localizing industry when neither transport costs nor market conditions demand a location at the market center. The raw materials source appears to have 1ittle or no locational influence on an industry when the cost of transport is negligible, or when the freight cost is substantially the same for raw materials and the finished products. Greenhut's theory of industrial location attempted to correlate the demand and market approach. Thus, there is an integration of cost and demand influences that are considered codeterminants of location. This integrated theory includes: cost factors, demand factors, and purely personal considerations. Only when all of these factors are considered in determining the location of an industry can an understanding of the forces for determining location be acquired. The core of Greenhut's theory is summarized as follows:

"... each firm entering the competitive scene will seek that site from which its sales to a given number of buyers (whose purchases are required for the greatest possible profits) can be served at the lowest total cost ..."1 
In time, the successful attempts of competitors to locate at the profitmaximizing site will so shrink the relative demand as to cut profits, thereby leading eventually to the state of locational equilibrium. Such equilibrium would find (1) marginal revenues equated to marginal costs, (2) average revenue tangent to average costs, and (3) concentrations and scatterings of plants in such order that relocation of any one plant would occasion 1osses. ${ }^{3}$ When applied to SPS, this theory has important implications. For example, partly due to the availability of hydroelectric power the Pacific northwest has attained a high concentration of aluminum manufacturing and aircraft plants that use this material. The source of electrical power for the aluminum industry is threatened by 1988 . Hence, the siting of rectennae in that region would be consistent with Greenhut's theory. This issue will be explored later.

\subsubsection{Spatial General Equilibrium}

The first comprehensive theory of general equilibrium using a spatial concept was developed by Walter Isard, in Location and Space Economy. ' Isard attaches great importance to the fusion of location theory with other branches of economic theory. Isard attempts this through application of substitution principles. The basic idea is that a general theory of location can be developed in a manner similar to other aspects of economic theory by applying the principle of substitution to the way an entrepreneur combines expenditure on the various factors of production in making his choice of location. Isard classified location factors into three groups. The first group includes transport and certain other transfer costs. Because these costs vary regularly with distance, they provide a relevant set of reference points -- whether raw materials, service, or market points -- that establish systematic variations of these costs over space. A second group of factors comprises costs associated with labor, energy, taxes, water, insurance, climate, and a number of other items. Although these items possess a relatively stable geographic cost pattern, they do not vary systematically with distance as do transport costs. By contrast, these costs vary independently of distance and direction. The third group includes those elements that cause agglomeration and deglomeration economies. The agglomeration forces include economies of scale, as well as the localization and/or urbanization of economies. The deglomerative forces include diseconomies within a firm, the rise of rents and costs of urban services, and the rise in the cost of food as the rise in the size of population settlement compels the 
importation of foods from greater distances. The agglomerative and deglomerative forces operate independently of geographical position.

Isard concluded that of the three groups, only transport costs, which are functionally related to distance, impart regularity to the spatial pattern of economic activities. Substitution analysis among various transport inputs provides an understanding of the geographic pattern of production and the impact of the friction of distance. ${ }^{1}$ Preliminary SPS rectennae sites are located in sparsely populated areas where transportation costs may be high. Thus, if Isard's theory is accepted, little relocation of industry may occur around the sites. The substitution concept has important implications for SPS which will be explored later.

\subsubsection{Recent Contributions}

There has been little progress during the last two decades in the elaboration of classical location theory. Although locational analysis has continued its development with new perspectives evolving, most of these contributions do not constitute new conceptual frameworks. Rather, they provide generalizations based on observations of the industrial world. ' The purpose of this section is to note these recent contributions but not extensively detail them.

The behavioral theory points out that economic man is assumed to be normative. That is, decisions are made under complete economic rationality (perfect knowledge). It is often pointed out that this is not true in reality, and that a rational optimal industrial location decision is impossible. Thus, the search for an industrial location is not for one that is optimal, but rather for one that will satisfy the needs of the decision-maker.

The general systems approach grew out of the concern for increasing specialization and the general inability to view problems in their totality. The systems approach recognizes that the totality of production factors must be considered by a firm desiring to secure a satisfactory location. Thus, one must examine the flow of information in order to understand the links and relationships between factors affecting the choice of location.

The growth pole theory notes that the economic space of a firm is determined, among other things, by a field of forces. As a field of forces, economic space consists of centers (or poles or foci) from which centrifugal 
forces emanate and to which centripetal forces are attracted. Thus, each center of attraction and repulsion has its proper field, which in turn is set in the field of other centers. The economic zone of influence is delimited by this process. Thus, growth poles are likely to be firms, industries or groups of firms and industries. It is within these "poles" that growth and change are generated. Connections between the poles (i.e., inputs and outputs) transmit the forces that are generated.

The stages theory indicates that over time, different sectors of the economy will assume lesser or greater importance. A historical sequence of events is hypothesized. The economy of an area develops initially around a primary activity -- agriculture, forestry, mining-- that provides an exportable surplus over local needs. The proceeds from these sales provide the means for importing items not produced locally, typically manufactured items. This spurs new stages of growth.

According to the agglomeration theory, the great concentrations of manufacturing through time are the product of a single thrust-specialization. The fundamental theme of this viewpoint is that the specialization of functions results in the specialization of areas or regions. It makes possible a distinction in function between town and country and further differentiates one area from another. Areal specialization becomes the corollary of functional integrated specializations simply represents the advantages of a particular locality.

\subsection{FACTORS AFFECTING INDUSTRIAL LOCATION}

A fundamental question in spatial location is: What are the factors that play a role in the world's industrial spatial patterns? This section will delineate several primary and secondary factors.

\subsubsection{Primary Factors}

Many theorists contend that transportation is the single most important factor in industrial location. Transportation is regarded as a major determinant of plant location in two respects: cost of service and type of service. If freight costs comprise a large part of total costs, the transportation factor may have to be economized. However, the desire to economize line haul costs does not necessarily signify its achievement. A prerequisite to the 
achievement of the reduced total shipping costs is that transfer costs must be accounted for. Vital transport data, therefore, are a combination of the ratio of freight cost to total cost and the difference in transfer burdens at alternative sites. Availability of certain types of transportation or points of converging transport systems are exceptionally important factors. Santini has shown that water transport is a key geographical determinant for many heavy industries. 15

The availability of raw materials is frequently a major locational factor. All manufacturing requires a supply of raw materials. Furthermore, raw materfals are not equally distributed over the earth, but are localized in certain regions. The influence of raw materials as a location factor has declined in the last 50 years for several reasons. The development of a network of transportation systems has facilitated the movement of raw materials and, as manufacturing has become more complex, there is relatively less processing of basic raw materials by individual manufacturers.' Santini's work also illustrates the importance of water transport for those industries processing large volumes of raw materials. ${ }^{15}$

Another major factor is the availability of energy. The principal uses of energy are to generate heat and provide power for manufacturing. Fossil fuels are used to provide both heat and power by numerous methods. By comparison, technologies that utilize renewable resources such as hydropower and the proposed Satellite Power System are primarily designed to generate electricity. Therefore, while the fossil fuels provide diverse forms of energy for almost the entire spectrum of modern industry, significant electricity consumption is confined to a narrower range of industries. The availability and cost of electricity is of key importance to the aluminum, petroleum, iron and steel, chemical, paper, and several other industries. These are the industries whose location pattern is likely to be initially affected by the development of renewable resources and the subsequent expansion of electric generating capacity in the U.S. Another important energy consideration is the importance of electricity availability relative to other location factors such as labor, transportation costs and the availability of auxiliary resources. For example, conventional electric generating plants are dependent upon water for cooling. SPS promises to remove this constraint and could, as a consequence, indirectly affect the distribution of industry. 
The cost, availability, stability, and productivity of labor are vital factors in every manufacturing enterprise. The growth of an industrial area is jeopardized if these labor conditions are not favorable. However, 1abor requirements are not uniform among industries. Certain industries require a large number of skilled workers; others require a large number of unskilled workers; and still others require varying numbers of each. Because the SPS receiving antenna may need to be located in relatively sparce population areas, labor-intensive industries may not relocate near the sites.

The market is an increasingly important location factor. There is frequently a cost advantage when a substantial local market exists, and this situation is enhanced when a good competitive position is maintained by serving several adjoining market areas.

\subsubsection{Secondary Factors}

Besides primary factors, there are many other factors that affect industrial location. These factors are not essential to the manufacturing process in themselves, but may so affect cost structures that they become vital in the location decision process.

The influence of physical environment including topography, climate, and water availability is important. Governmental policies including subsidies, government ownership, legal and legislative actions, taxation, environmental regulations, etc., are also important. Personal considerations such as the existence of capital in a locality, the favorable impression of a chamber of commerce, or existence of a university may be important. Depending on the nature of the industry, the SPS could attract or discourage relocation when these factors are considered.

\subsection{APPROACHES FOR REGIONAL AND LOCAL ANALYSIS}

Many techniques for analyzing industrial location have been developed. Although it is beyond the scope of this paper to consider them all, brief descriptions for several important procedures are included. These techniques include: comparative cost analysis, input-output techniques, correlation and regression analysis, and export-base computer simulation techniques. 


\subsubsection{Comparative Cost Analysis}

Comparative cost analysis is a procedure for comparing locational costs for a plant at different sites. The objective of comparative cost studies is to determine in what region(s) the industry could achieve the lowest total cost of producing the required output and delivering it to the market. Such studies frequently reveal that certain component costs do not vary among sites. Comparative cost studies have proven advantageous in some types of industrial developments. When there is a change in the factors of production, new areas may gain economic advantages that attract industry while traditional areas may lose certain of their advantages. A technological change frequently alters locational advantages. Comparative cost analysis is a useful tool when applied to one industry and it is important to use substitution analysis so that the analysis can consider alternative locations. What has been called the "bliss point" location would be one where no further substitutions at another location could result in a cost reduction. Comparative cost analysis is thus within the Weberian framework of least cost analysis. Comparative cost studies assume that the price/cost structure and the market are given. These assumptions are untenable where the totality of a region is analyzed by industry found in a particular region. As a result other types of analysis are superior when the interrelations among industries in a region are to be analyzed.

\subsubsection{Input-Output Technique}

Several significant input-output works have been reviewed for this section. ${ }^{6,7,14}$ Input-output (I-O) theory is fundamentally concerned with the interrelations arising from production. ${ }^{6}$ Its major purpose is to measure the magnitude of the flow of goods and services from one level of production to another. The I-O method of analysis is thus an attempt to combine economic theory with an empirical approach to the study of production.

The basic premise of the I-O model is that it is possible to divide all productive activities in an economv into sectors whose interrelations can be expressed in a set of input functions. 
An I-O analysis is developed by the construction of a transactions table. This table is a matrix that shows how inputs and outputs of each industry are distributed among other industries and sectors of the economy. The transactions table can be utilized for futures projection. Its major advantage is that it ensures that projections for individual industries and sectors will add to a total projection.

The I-O technique's greatest utility is for short-run forecasting. However, there are problems related to I-O analysis. It requires tremendous personnel and capital resources. Data availability also strictly limits the use of I-O analysis. Finally there have been questions as to the adequacy of $I-0$ analysis for such aspects as economies of scale, localization economics, and regional cost variations. Hence, the I-O technique has been judged inappropriate for predicting locations of economic activity.

\subsubsection{Correlation and Regression Analysis}

To analyze the variables that are normally related to understanding the spatial location of industry, multiple correlation and regression analysis may be used as valuable analytical tools. Correlation methods provide measures whereby the past relationship between two or more variables can be identified. Multiple regression techniques are used to test theories of location patterns and generate equations which may be used to predict location of industries with no statistical records (i.e., no history). It cannot therefore be used specifically for SPS, although it can be used to learn about industrial location in general.

The primary limitation of this method is that a variety of high-quality data must be collected. Another limitation is that regression analysis explains locational patterns on the basis of conditions at a particular time. In a mature industrial region, many industries have located under sets of factors that have changed over time. Finally, a strong statistical relationship does not necessarily indicate a strong cause-and-effect relationship.

\subsubsection{Export-Base Theory}

Export-base theory involves making a distinction between industries in a region. A dichotomy is made between those activities in which a region specializes, and those activities which are not unique to it. ${ }^{8}$ The economic 
specialties are called basic activities, and their consequentional activities are referred to as nonbasic or secondary activities. The basic industries are those that produce for export from the region, while secondary industries serve the local market. The basic activity is one that has exogenous demand (independent of the region's level of activity), while nonbasic activity is endogenous (dependent on the region's level of basic activity). An increase in the external demand for a basic industry's good results in an increase in the activity of the nonbasic industries as well.

A major tenet of the export-base approach is that when a basic industry grows, it will increase nonbasic economic activity. ${ }^{16}$ The size of the increase depends on the relationship between basic and nonbasic activities. It is the addition of basic employment that acts as a catalyst to increase the nonbasic employment. Thus, if growth is to occur, the basic component of employment is the driving force.

Export-base theory and location theory are connected in four ways. First, economists are concerned with the factors that cause basic industries to locate in a region; thus, export-base theory may be considered an extension of location theory. Second, export-base theory, as an extension of location theory, emphasizes the role of the economic base in attracting capital. Capital flows to the regional specialties offer higher rates of return on investment. Also, externally supplied capital not only increases the productive capacity of the region, but it also improves the economic environment for future growth. Third, expanding export-base industries such as SPS may serve to attract other export industries causing still further growth. Fourth, secondary impacts (nonbasic employment and income) accentuate growth. Each of these effects will be examined in Sec. 3 .

It should be noted that we have empahsized that energy availability and price are important determinants of industrial location. However, by itself, energy may not be a sufficient incentive for industry to relocate. The importance of energy in effecting the relocation of economic activity and population can be assessed only through further research. It is especially important to examine the effect SPS generated electricity may have on industrial relocation and population redistribution. 
In order to conduct the required research, the theories of industrial location reviewed in this section are needed to predict what types and levels of basic economic activity may be attracted to rectenna-bearing regions. Based on these predictions of industrial attraction, empirical methods can be used to estimate employment and population changes that may derive from relocations of manufacturing activity. There are, however, two distinct schools of thought about the causal relationship between economic change and population movement. Export-base theory holds that population follows change in economic activity and employment; whereas another school of theorists (most notably represented by Borts and $\operatorname{Stein}^{17}$ and $\mathrm{Muth}^{18}$ ) contend that change in economic activity and employment follow population change. The most important differences between these theories are described in Sec. 3 and the Appendix. A case is made that export-base theory is the more valid one upon which to build a methodology for estimating changes in regional employment and population. It is also discussed in Sec. 3 how a methodology derived from export-base theory can be used to estimate the employment and population effects of industrial relocations on regional or local levels. 


\section{SECTION 2 REFERENCES}

1. Miller, Willard E., Manufacturing: A Study of Industrial Location, Pennsylvania State University press, University Park, Pennsylvania (1977).

2. Hoover, Edgar M., Jr., Location Theory and the Shoe and Leather Industries, Harvard University press, Cambridge, Massachusetts (1937).

3. Greenhut, Melvin L., Plant Location in Theory and Practice: The Economics of Space, The University of North Carolina press, Chapel Hil1, North Carolina (1956).

4. Isard, Walter, Location and Space Economy: A General Theory Relating to Industrial Location, Market Areas, Land Use, Trade, and Urban Structure, The M.I.T. press, Cambridge, Massachusetts (1956).

5. Smith, David M., Industrial Location: An Economic Geographical Analysis, John Wiley and Sons, Inc., New York, New York (1971).

6. Almon, Clopper, Jr., 1985 Interindustry Forecasts of the American Economy, D.C. Health and Company, Lexington, Massachusetts (1974).

7. Miernyk, William H., The Element of Input-Output Analysis, Random House, New York, New York (1965).

8. Stenehjem, Erik J., Forecasting the Local Economic Impacts of Energy Resource Development: A Methodological Approach, Argonne National Laboratory report ANL/AA-3 (Dec. 1975).

9. Hotelling, Harold, Stability in Competition, Economic Journal, 39:41-57 (March 1929).

10. Chamberlin, Edward H., The Theory of Monopolistic Competition, Harvard University Press, Cambridge, Massachusetts (1933).

11. Lerner, A.P., and H.W. Singer, Some Notes on Duopoly and Spatial Competition, Journal of Political Economy, 45:145-186 (1937).

12. Smithies, Arthur F., Optimum Location in Spatial Competition, Journal of Political Economy, 49:423-439 (June 1941).

13. Ackley, G., Spatial Competition in a Discontinuous Market, Quarterly Journa1 of Economics, 56:212-230 (1942).

14. Emerson, Jarvin M., and Charles F. Lamphear, Urban and Regional Economics: Stmucture and Change, Allyn and Bacon, Boston, Massachusetts (1975).

15. Richardson, Harry W., Regional Economics: Location Theory - Urban Stmucture - Regional Science, Praeger Publishers, New York, New York (1969).

16. Santini, Danilo J., An Econometric Model of Transportation Infrastructure as a Determinant of Intraurban Location, Journal of Regional Science, 18 (1) (1978). 


\section{SECTION 2 REFERENCES (cont'd)}

17. Borts, George H., and Jerome L. Stein, Economic Growth in a Free Market, Columbia University Press, New York, NY (1964).

18. Muth, Richard F., Migration: Chicken or Egg?, The Southern Economic Journal, pp. 295-306 (January 1971). 
Having discussed those factors that determine industrial location and some of the theoretical approaches that can be used to predict industrial location, we turn in this section to questions of how population shifts are related to geographic shifts of industry. At one extreme, it is possible to argue that industrial location shifts cause population shifts (migration) but not the reverse. Equally extreme is the position that migration causes industry to follow and no reverse linkages are present. Under certain circumstances, either one of these positions can be correct. In the first case, the opening of a mineral extraction operation in a remote rural location will require that population follow to provide labor for the operation. An example of the second case would be the development of a retirement community in a location with sunshine and other positive environmental attributes that would not otherwise attract business. Retirees obviously would not move to such a location for jobs, but some service businesses and perhaps light industry would move to such a retirement community to serve the retired population. The important issue is not whether one case or another can be correct but, rather, what is the typical mechanism of economic and demographic growth?

\subsection{THEORY}

The two different possibilities for population/industrial location shift interactions are exemplified in theory by (1) the previously discussed exportbase theory in which the location of industry explains the migration of population, and (2) the Borts and Stein ${ }^{1}$ hypothesis that differential changes in employment are induced by differential rates of in-migration. There are several works that attempt to use and verify one or the other of these two theories. However, there is only one widely recognized attempt to test both theories simultaneously in order to determine which is the more generally valid. This is the Migration: Chicken or Egg? article by Richard Muth. ${ }^{2}$ In this study, Muth constructs a two-equation model that simultaneously estimates migration and total employment growth of large U.S. urban areas during the period 19501960. His results support the Borts-Stein hypothesis to a greater degree than the export-base theory. A more recent, and less known, study of population/ employment growth is a Ph.D. dissertation by Santini. ${ }^{3}$ In this study, Santini constructs a four-equation model that simultaneously estimates center-city 
population growth, suburban population growth, manufacturing employment growth, and nonmanufacturing employment growth. This study examines Standard Metropolitan Statistical Areas (SMSAs) in and near the North Central Census Region for both the 1950-1960 and 1960-1970 decades. Santini's results strongly support the export-base theory and they demonstrate the importance of characterizing migrants and non-migrants separately if export-base modeling is to be done correctly. It is described in Sec. 3.2 how the Argonne Social and Economic Assessment Model (SEAM) implements export-base theory to predict population growth from economic development (i.e., the creation of jobs).

\subsubsection{The Muth Model}

Muth cites Borts and Stein ${ }^{1}$ as the original proponents of the theory that population growth causes employment growth. As examples of the exportbase theory, he cites Blanco, ${ }^{4}$ Mazek, ${ }^{5}$ and Lowry. ${ }^{6}$ In the export-base models cited by Muth, it is the concept of potential unemployment that is supposed to be the cause of migration. Potential unemployment is the amount that would have existed at the end of the period had there been no migration. To test the hypothesis that population growth causes employment growth, it is necessary to distinguish between natural increase in the labor force due to local entrants (natural increase), and increase due to migration. Muth estimates the natural increase and subtracts it from total labor force increase to compute an estimate of migration into the labor force. Muth then presents a twoequation model in which his estimates of migration into the labor force and total employment growth are the independent variables of the two equations. Natural increase of the labor force is treated as an independent variable in both equations. Based on the test results of this model, Muth found it difficult to accept the export-base theory as a fundamentally correct description of the urban growth process. On the other hand, while his results provided more support for the Borts and Stein hypothesis than for the export-base theory, he could not (and did not) assert that his results supported Borts-Stein to the exclusion of export-base effects. In short, he implied that neither theory provides an accurate description of the growth process.

\subsubsection{The Santini Mode1}

The Santini mode $1^{3}$ is similar to the Muth model in the sense that it simultaneously estimates employment and population growth. The most important difference between the two models is that Santini disaggregates employment 
growth into manufacturing and nonmanufacturing employment growth. This allows him to make a distinction between the basic and nonbasic sectors as required to verify (or refute) the export-base theory. Santini uses the Lowry Model of Metropolis ${ }^{8}$ as the model of export-base theory. The Lowry model is an appropriate export-base paradigm to use because it spawned several other urban simulation models in the field of transportation planning.

The fundamental differences between the Borts-Stein and export-base theory that were tested are the following:

1. Export-base theory predicts:

a. No effect of population growth on basic sector employment.

b. A positive effect of basic and nonbasic sector employment growth on population growth.

c. A positive causal relationship of population growth on nonbasic sector employment growth.

2. Borts-Stein theory predicts:

a. A positive effect of population growth on employment growth.

b. No causal relationship of employment growth on population growth.

Santini found, in tests of several versions of his model, that the export-base predictions were verified in every case. His results, unlike those of Muth, do not allow for equivocation. They indicate that the export-base model is a fundamentally correct description of the urban growth process.*

\subsection{ECONOMIC DEVELOPMENT, EXPORT BASE, AND POPULATION CHANGE}

Reduced to its essence, export-base theory holds that the growth of a region depends upon the growth of its "export" sector. The implication is that the expansion of demand for goods and services produced within a region and sold for export outside the region is the driving force behind regional growth. As Richardson ${ }^{9}$ has pointed out, an exogenous increase in the production of goods for sale and distribution beyond the borders of a region sets off a multiplier process of growth in the provision of locally produced and consumed goods and services. Thus, stimulating activity within the basic

\footnotetext{
*Santini's model and test results are summarized in a paper that has been submitted for publication. Until it becomes available in the outside literature, copies of this paper may be obtained by contacting the author.
} 
(export) sector of a region produces a multiplier response in the nonbasic secondary sectors. There are two effects responsible for this multiplier response. First, an "indirect" effect occurs as the exporting firm, in order to expand (or initiate) production, purchases raw and intermediate goods from existing firms in the region. Secondly, an "income-induced" effect occurs as increased production in the firms directly and indirectly stimulated is translated into increased consumer demand for, and hence production of, the goods and services provided by the retail, commercial, and service sectors of the region.

\subsubsection{The Causa1 Relationship between Export-Base Employment and Population Change}

Export-base theory has been used by economists and regional analysts to explain the relationship between exogenous increases in export sector activity and the growth in employment and population within a region. As a first step in this process, estimates of the size of the multiplier effect (the indirect and income-induced changes in the secondary sector consequent to exogenous changes within the basic sector) must be made. The manner in which these multipliers are derived varies considerably in sophistication. Equation 1 illustrates a simple ratio approach to multiplier estimation.

$$
M_{i}=\frac{T \cdot E \cdot_{i t}-T \cdot E \cdot_{i t-1}}{B \cdot E \cdot_{i t}-B \cdot E \cdot_{i t-1}}
$$

where:

$$
\begin{aligned}
& \begin{aligned}
\text { T.E. } & \text { it }= \\
& \text { economic activity in region } i \text { at time period } t,
\end{aligned}
\end{aligned}
$$

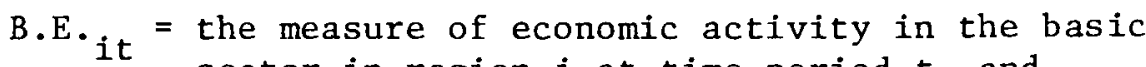

$$
\begin{aligned}
& \text { sector in region } i \text { at time period } t \text {, and } \\
& \begin{aligned}
M_{i} \quad= & \text { the "multiplier" for this measure of economic } \\
& \text { activity in region } i \text {. }
\end{aligned}
\end{aligned}
$$

When the measure of economic activity selected is employment, $M_{i}$ is termed the regional employment multiplier. It reflects the previous regional response of changes in total employment (basic plus secondary) to increases (or decreases) in basic employment and is used to project the basic to secondary relationship for given future changes in basic employment. Multiplying annual (or period) exogenous changes in basic employment due to industrial relocation or expansion by $M_{i}$ provides a measure of the total employment response (basic plus secondary) within the region. 
Estimates of total new employment in the basic and secondary sectors of a region are obtained using multipliers derived from export-base theory. Since, as the theory indicates, the growth of a region is dependent upon the stimulus provided within the basic sector, the effect upon regional population is straightforward. In the demograhpic accounting framework, changes in the size and composition of the regional population are a function of births minus deaths plus net migration. Consistent with the theory of export-base, net regional migration is, ceteris paribus, a consequence of the stimulus provided by increased basic economic activity.

According to export-base theory, the following effects would be expected to occur as a result of the relocation within a given region of an industry (or firm) engaged in basic economic activity. The presence of the new firm creates new basic employment financed by receipts drawn from outside the region. In addition, the presence of the new firm can be expected, depending upon the industrial diversification of the region, to lead to direct increases of demand for the products of regionally-based firms. As these firms expand production, still more job opportunities are created within the region. Finally, as the revenues generated by the new firm are passed as income to its employees and to those persons engaged in supplying goods and services to the new firm, the demand for products and services provided by local retail, commercial, and service establishments increases. This new income-induced demand has the effect of generating still more jobs as regional merchants expand their operations in response to the increased consumer demand within the region.

We have described the mechanisms of export-base theory, now we will discuss some of the various ways that shifts in the export-base can be absorbed or assimilated by the local community. We examine three cases. First, is the case where basic employment growth is greater than that which can be handled locally in a small region. Second, is the case where basic growth merely sustains a region. Finally, we examine a case where basic growth is insignificant relative to the regions' size.

The size and composition of a region's population are influenced by the creation of new basic and secondary (indirect and income-induced) jobs and income that influence migration. In those regions where the number of basic and secondary jobs created exceeds the number of available, appropriately-skilled workers (e.g., regions with small local populations), new workers and their 
households move into the region in quest of the unfilled jobs and the population expands. In regions where natural increase of the labor force is adequate, no migration will be necessary. However, the basic and secondary increases in jobs and incomes may reverse historic patterns of out-migration in economically stagnant or declining regions. Such regions are exemplified by rural areas and old manufacturing areas. Reducing negative net migration among persons in their productive and child-bearing years will contribute to the growth of regional population, even if it only reduces the rate of decline. Finally, in those regions with large populations, low dependency ratios, * and an expanding economy, the introduction of a new basic firm of moderate size may have no noticeable effect on population growth in the region. Thus, as these examples illustrate, the magnitude of the effect that a new basic economic activity will have upon net population changes is a function of the number of basic and secondary jobs created relative to the assimilative capacity of the region where assimilative capacity refers to the economic characteristics (e.g., industrial mix and integration, and labor force characteristics such as unemployment, size, availability, and worker skil1s), and demographic characteristics (e.g., population size and density, dependency ratio, fertility, mortality and net migration) of the region.

In those instances where new basic economic activity is attracted to areas having relatively low capacities to absorb the basic, indirect, and income-induced changes in employment and income, problems of providing housing, health care, education, safety, and recreational services arise. Examples of such problems are well-documented in the case histories of western energy "boom towns." For example, with an exogenous increase in energy resource development in Sweetwater County, Wyoming, 8,000 new basic and secondary jobs were created between 1970 and 1974. Because the pool of available workers in and around Sweetwater County was insufficient to fill the number of new jobs, the population jumped from 18,900 to 37,000 persons during this period. With this almost two-fold increase in population, a shortage of 1,400 homesites was experienced. The presence of this new population also created immense pressure on the public infrastructure in Sweetwater County. During this period, the county experienced an unabated shortage of 124 school classrooms for new

*The dependency ratio is the number of persons under 16 and over 65 years of age divided by the total population. 
primary and secondary students, an eight-fold increase in mental health caseloads, a $200 \%$ increase in the patient-doctor ratio, a $60 \%$ rise in crime, and deficits in almost all of the other municipal and county facilities that people rely upon to maintain acceptable life standards. ${ }^{0}$ With the failure of the public and private infrastructure to provide adequately for the new and old residents, labor turnover rates rose and productivity in both the basic and secondary sectors of the economy declined.

The infusion of new basic economic activity has long been viewed as a lever to be used by communities to increase local employment, add to local income, reverse historic patterns of out-migration and declines in productive populations, and generally revitalize the character of the public and private infrastructure. However, as both the description of the relationship between economic activity and population change in export-base theory and the example of Sweetwater County make clear, the consequences of new basic economic activity are not always desirable. Whether the stimulus provided by new basic activity will have beneficial or detrimental effects is a function of the size of the stimulus relative to the assimilative capacity of the region.

\subsubsection{An Export-Base Model of Employment and Population Change}

The establishment of rectenna sites in large, low-density areas creates the potential for adverse social and economic impacts of the type, if not the severity, experienced in Sweetwater County, since:

- large land areas of low population density are likely to have low assimilative capacities;

- the construction and operation of a rectenna represents new basic activity; and

- the existence of a rectenna may attract additional basic industry, hence even greater secondary economic activity and population growth.

Because the potential exists for adverse social and economic impacts to occur in areas hosting the new rectennae, forecasts of the likely employment and population effects among candidate sites should be projected and used as a criterion of acceptability in the final site selection process.

The Social and Economic Assessment Model (SEAM) was recently developed by the Economics and Social Sciences Section in the Energy and Environmental Systems Division of Argonne National Laboratory. It employs the techniques 
of export-base analysis to evaluate employment and population effects of energy or industrial development on any county, or combination of counties, in the continental United States. SEAM provides the following outputs at the county level:

- Annual projections of baseline (non-impact) population by age, sex, and race;

- Annual direct employment requirements;

- Annual estimates secondary employment created by the presence of the new industry;

- Annual projections of the locally available work force including commuters from adjacent counties;

- Annual projections of the size and composition of in-migrant households;

- Annual housing needs and the subcounty spatial allocation of the new population; and

- Annual estimates of the increased public service needs of the new population and the costs of providing them.

A schematic diagram of the SEAM model is provided in Fig. 3.1 .

In making its projections, the model first forecasts the annual change in the national population of the host county to provide a baseline from which the future labor force can be determined and against which the impact of the new basic industry can be assessed. These projections of the change in the size and composition of the county population are made using the cohort-component method. Given these projections, the annual employment requirements of the new basic activity are determined and employment multipliers, derived from export-base theory, are used to estimate the total indirect and income-induced employment effects. These estimates of increased secondary employment are lagged to better approximate the number of such jobs created in each annual period.

Given estimates of the total number of jobs (basic and secondary) 1ikely to be created in each year of the new project's life, the size and skill mix of the locally available labor force must be determined. Forecasts of the baseline changes in the size and composition of the host county and all counties whose centers of population are within 60 miles of the assumed site are prepared by the model. In each county, the labor force participation rates (LFPR) by age and sex cohort are compared to national LFPRs and, where local rates are lower, the local labor force is assumed to grow to the national level for that cohort. The unemployed in the local area are added to these estimates to 


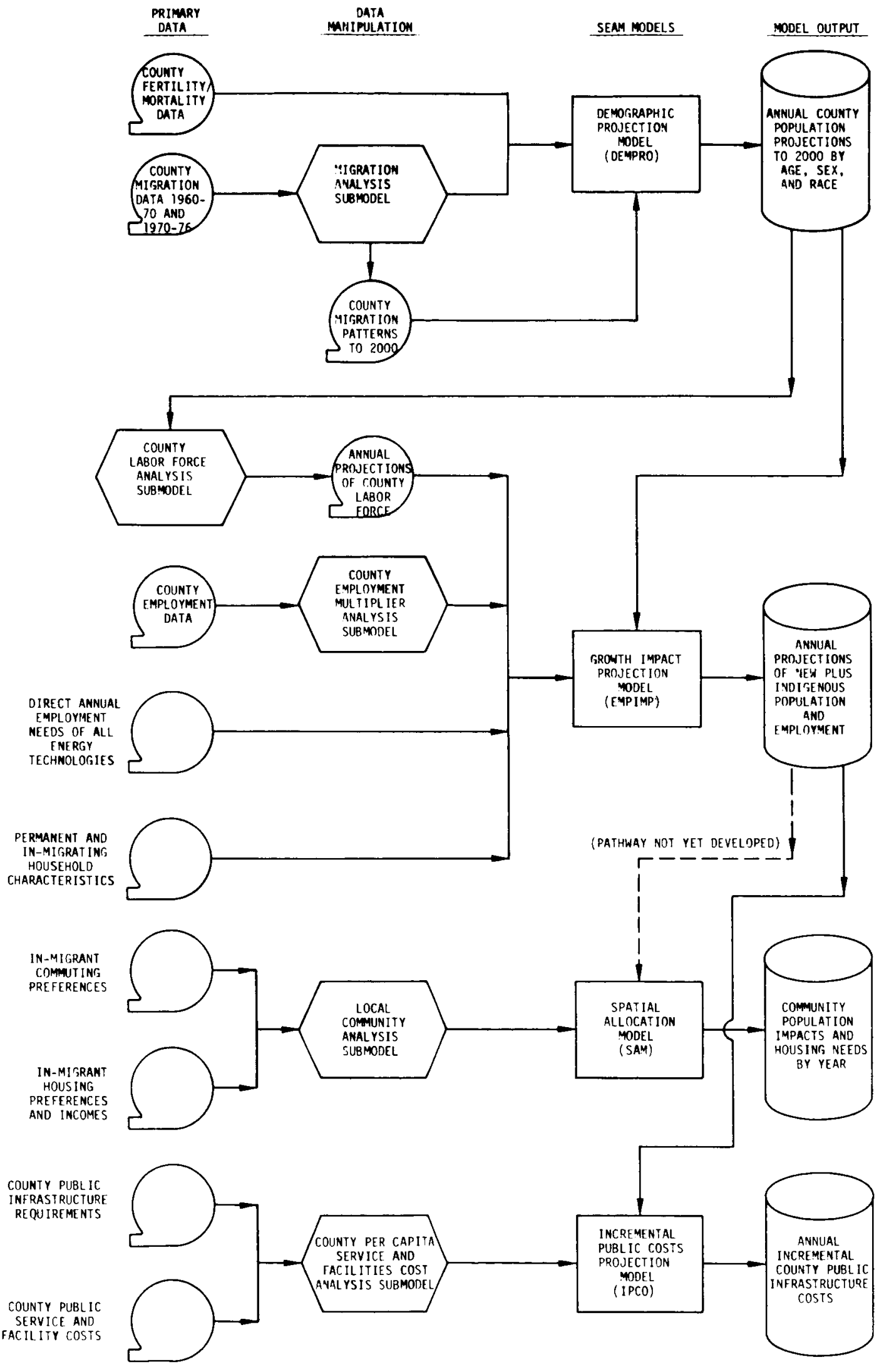

Fig. 3.1. Data and Component lodels of SEAM 
yield the total size of the available labor force in each year. This pool of men and women is characterized by age and skill type using local data and the total available work force is divided into potential basic and potential secondary workers. Finally, the size of the available work force is reduced by the estimates, taken from a national highway transportation study, ${ }^{11}$ of the percentages from each adjacent county who may be unwilling to commute different distances.

Having estimated both the annual number of new basic and secondary jobs and the annual availabilities of local basic and secondary workers, the model determines the number and age distribution of persons (and households) 1ikely to in-migrate. The number of in-migrants is estimated by assuming that each job unfilled by local residents will attract a new worker household to the area and that each such household has 1.2 productive members. Thus, the total annual change in the size and composition of the host county due to the new basic activity is determined. The age distribution of the migrants is then estimated by assuming that the U.S. migrant age profile applies to these migrants as well. Age distributions of migrants are substantially different from nonmigrants. The relative age profiles of the two groups can have significant effects on future growth rates as well as education and other service needs.

The model next provides estimates of the housing needs and community settlement patterns of these new households using a preference-maximizing, income-constrained, linear programming system. Essentially, this algorithm recognizes that among the in-migrant population there are different preferences for housing, different preferences for community types, and different abilities to pay for alternative dwelling units. It maximizes each household's preferences for housing type and location subject to their abilities to pay for these features.

Once the new households are "assigned" to residences in different communities, the model determies the increased public service needs of the increased population and determines the annual costs of providing them. A special study of the service needs and costs was conducted to supply this data. This study surveyed the per capita requirements and costs of 11 public services in communities of five different types (e.g., rural, small urban, independent 
outlying), and five different sizes (e.g., less than 2,500, 2,500-5,000) in each of the nine Census regions. The estimated needs of communities are quite specific owing to the level of detail in this study.

The model, as explained, forecasts the nature and magnitude of the social and economic effects that a new basic activity is likely to have upon the host county and its communities. It provides a standardized measure of the magnitude of impact by translating the effects of employment and population changes into the dollar costs of adjusting the public service infrastructure. It can and should be applied to an analysis of potential rectenna sites to determine the relative benefits (in terms of increased employment and income) and costs (in terms of housing and services) of alternative siting patterns. The public cost estimates, in fact, may be explicitly considered as a criterion in the final selection of rectenna sites.

\subsubsection{Relevance of the Social and Economic Assessment Model (SEAM) to SPS}

Shifts in the location of basic economic activity that may be induced by the proposed satellite Power System (SPS) have not been studied and, hence, there is a need for substantial investigation. As indicated above, SEAM is a we11 developed and usable model. Using this tool as a foundation, ANL researchers will be able to examine the prospective relationships of industrial (i.e., basic employment) and population relocations to rectennae siting and to forecast potential socioeconomic impacts. However, further research is needed to develop the link of industrial relocations to the availability and cost of electric power. This point is discussed further in the next section. 


\section{SECTION 3 REFERENCES}

1. Borts, George H., and Jerome L. Stein, Economic Growth in a Free Market, Columbia University Press, New York, NY (1964).

2. Muth, Richard F., Migration: Chicken or Egg?, The Southern Economic Journal, pp. 295-306 (January 1971).

3. Santini, Danilo J., Urban Acquisition and AlZocation of Hroman Resources: Two Integrated Econometric Models Accounting for Urban Function, $\mathrm{PhD}$ Dissertation, Northwestern University (1976).

4. Blanco, Cicely, The Determinants of Interstate Population Movements, Journal of Regional Science, pp. 77-84 (summer 1963).

5. Mazek, Warren, The Efficacy of Labor Migration with Special Emphasis on Depressed Areas, Working Paper CUR-2, Institute for Urban and Regional STudies (June 1966).

6. Lowry, Ira. S., Migration and Metropolitan Growth: Two Analytical Models, Chandler Publishing Co., San Francisco (1966).

7. Santini, Danilo J., An Econometric ModeZ of Transportation Infrastmicture as a Determinant of Intraurban Location, Journal of Regional Science, 18(1), (1978).

8. Lowry, Ira. S., A Model of Metropolis, Memorandum RM-4035-RC, The Rand Corporation, Santa Monica, CA (1964).

9. Richardson, H.W., Regional Economics, Preager Publishers, New York (1969).

10. Gilmore, John S., and Mary K. Duff, The Sweetwater County Boom: A Challenge to Growth Management, University of Denver Research Institute, Denver, Colorado (July 1974).

11. Hummon, N., and D. Sharp, Nationwide Personal Transportation Survey, U.S. Department of Transportation, FHWA (1970). 
This section deals with the issues of industrial relocation and subsequent migration of population that may result from deployment of the Satellite Power System (SPS). Except for a brief overview of the SPS concept, this discussion focuses on terrestrial operations; specifically, the effect that large rectennae sites may have on the future distribution of economic activity and human population in the U.S. This discussion indicates how the literature reviewed in Secs. 2 and 3 relates to the future examination of these issues. Study of the effects resulting from development and operation of rectennae in the U.S. is emphasized. Given the desire to interface this white paper with other aspects of the societal assessment, some attention is also given to the related issues of public acceptance of rectenna siting, the consequences for international redistribution of industry and population, and the centralization of society. Some broader aspects of the general industrial expansion expected to accompany SPS deployment are also mentioned.

\subsection{DESCRIPTION OF THE SPS CONCEPT}

The many elements and subelements comprising the SPS concept have been grouped in several ways, but one aggregation suggested by NASA has been most useful in considering the particular issues addressed in this white paper. NASA places elements of the SPS concept in four categories: (1) the satellite power station; (2) ground receiving and distribution sites; (3) manufacturing, construction, and maintenance; and (4) space transportation. ${ }^{1}$ The NASA overview of these categories follows:

Satellite, Power Station

This element encompasses the power conversion options being studied. In addition to the photovoltaic and thermal solar energy conversion options, contractor studies are being performed on nuclear energy conversion systems. Each conversion option uses a rather similar microwave power conversion and transmission system as part of the satellite power station.

Ground Receiving and Distribution Site

This element includes the receiving antenna for the microwave beam, the utility interface with the related electric ground distribution system, the safety system related to microwave exposure protection and to the safety of maintenance and service activities, and the maintenance and service system. 
Manufacturing, Construction, and Maintenance Operations

This element includes ground and orbital operations and their respective systems that support the required manfuacturing, construction, assembly, and maintenance activities. A special operations management activity ties together equipment and manned operations and transportation and logistics requirements.

Space Transportation

This element consists of five transportation systems necessary to provide operational satellite power systems: the heavy lift launch vehicle (HLLV), the personnel launch vehicle (PLV), the cargo orbital transfer vehicle (COTV) system, the personnel orbital transfer vehicle (POTV) system, and the local space transportation vehicle (LSTV) systems.

\subsection{ISSUES RELATING TO GROUND RECEIVING AND DISTRIBUTION OF SPS ENERGY}

The remainder of this section focuses on the economic and demographic consequences expected to result from operating a large number of 5-GW SPS rectannae in the U.S. The issues examined have been grouped for this discussion according to five topics: (1) siting (i.e., pre-deployment); (2) construction, operation and maintenance after deployment; (3) public acceptance of SPS;

(4) affects on international migration of economic activity and population and;

(5) other implications and problems.

Except for mention of the Earth-based take-off and landing facilities for space transportation, all of the issues addressed are directly related to terrestrial impacts of the rectennae. This is because the rectennae are the primary determinants of land needs and the subsequent displacement of population. Furthermore, the location of these receiving and distribution facilities will directly affect the economics of SPS electricity pricing which may in turn influence industry to move nearer to the power sources. These moves may foster either the centralization or decentralization of society.

\subsubsection{Siting}

To a large extent, any relocation of industry and population effected by SPS will depend on siting of the large microwave receiving and electric distribution facilities that are required for the envisioned 5-GW satellites. Using the existing U.S. standard for microwave radiation exposure, each elliptical rectenna would require approximately $132 \mathrm{~km}^{2}$ of land. ${ }^{2}$ Full deployment 
of a 60 satellite (300-GW capacity) system would therefore require approximately $7900 \mathrm{~km}^{2}$, or about $0.09 \%$ of the total U.S. land area devoted to rectenna sites. ${ }^{3}$ Two preliminary siting studies ${ }^{4,5}$ indicate that the rectennae would need to be located in rural areas and one of these studies indicates that the rectennae may need to be clustered to optimize the avoidance of densely populated areas, with the availability of relatively cheap land and proximity to load centers or utility tie points.

Regardless of what secondary siting criteria are included, the primary need to diffuse microwave reception for safety means that rectenna sites will be located in rural areas and they may be clustered in presently underdeveloped regions. Hence, the costs for facilities to transport electricity from the rectenna sites to existing loads or the costs of relocating loads nearer the rectennae will have to be absorbed. All of the questions relating to SPSeffected relocations hinge on the trade-offs between these two basically different options. In this regard, there are two issues that need further study. First, what are the trade-offs between distributing the capital costs of transmission to the user through electricity rates (average cost pricing) or distributing these costs to society through taxes (marginal cost pricing)? Some other pricing options worthy of study include peak load and off-peak pricing. Second, what effect would implementation of these options have on the spatial distribution of industry and population?

The cost of transmitting SPS-generated electricity to industrial load centers is central to the concerns of this white paper. However, it may not be economically feasible to transmit the power over long distances from rural rectenna sites through the grid to existing manufacturing centers. If this is the case, the total cost of rectennae siting will include redistributing a portion of the load, conversion of existing land-uses, and construction of the rectenna consisting of land acquisition, preparation of the site, transport of materials, and assembly of the elements. An important policy question is whether the mere availability of SPS-generated electricity will provide sufficient incentive for firms to absorb the costs to move to regions containing SPS sites. Will there be some period of the day (year) in which it will pay to charge very little for SPS electricity to encourage its use? It should be noted that this is how the Bonneville Power Authority attracted aluminum manufacturing to the 
Pacific Northwest. Some industry will undoubtedly find a way to use cheap power during troughs in conventional demand patterns. Nevertheless, it may also be necessary (especially if the costs of developing the system are to be outweighed by revenues in a reasonable amount of time) for the government to stimulate the use of SPS power through industrial relocation subsidies, tax incentives, loan guarantees, or other programs such as electric price discounts to initial users.* Regardless of what mechanisms are ultimately used, locational shifts of industry and population will undoubtedly depend upon how the capital costs of SPS power transmission and/or industrial relocation are distributed.

Before the consequences for industrial and population agglomeration can be studied seriously, scenarios that bound the costs associated with transmission and industrial location must be developed. Just as important, alternatives for the payment of these costs must be established as the basis for further study.

Another economic and demographic issue directly related to SPS rectennae siting is the effect on labor. The large rectenna size means that population will be displaced and that varying degrees of economic disruption and job dislocations will be realized at different sites that are selected. New jobs will be created by construction of the rectenna as well as construction of industries moving into the region to be near the power source. However, the extent to which local populations can assume the new jobs will depend upon the skills needed for the new activities and the size and skill mix of the indigenous labor pool. If significant numbers of the rectennae are sited in developed regions of the country, as suggested in the NASA study, ${ }^{4}$ the impact on population displacement may be substantial but the impacts of relocation may be minimal given the proximity of rectenna sites to loads. Conversely, if significant numbers of the rectennae are sited in undeveloped regions of the country as suggested by the Arthur D. Little (ADL) study, ${ }^{5}$ population displacement may be minimal but the impacts of relocation and economic development may be substantial. Study of the economic and demographic impacts from SPS requires

\footnotetext{
*It should be emphasized that current law (e.g., the Rural Development Act) and existing political structure of the country would prevent the implementation of any growth policy that would give economic advantages to develop new areas at the expense of encouraging dislocations from existing centers of economic activity. Given this legal and political atmosphere, the appropriateness and consequences of government incentives must be carefully examined before they can be seriously considered as policy suggestions.
} 
serious evaluation of alternative siting patterns as decidely different as those presented in the NASA and ADL studies.*

\subsubsection{Deployment}

Once a rectennae siting pattern has been established, its implementation will generate impacts during both the construction and operation phases of each project. This section focuses on those post-siting issues.

\subsubsection{Rectenna Construction}

Before construction actually begins on a rectenna, but after a particular site has been selected, some preliminary impacts can be expected from land speculation and limited population growth. These initial impacts reflect the anticipation of accelerated development and they will influence the availability and cost of land and labor which are primary factors affecting the subsequent attraction of industry. Any study of impacts from industrial and population relocation should examine these initial effects. However, to a certain extent, any such examinations must result in forecasts that are conjectural. In the absence of any actual experience with SPS, the investigator must rely on scenarios about the future demand for and availability of electricity and the future levels of economic activity attracted to areas around the rectenna sites or regions in which they are to be located.

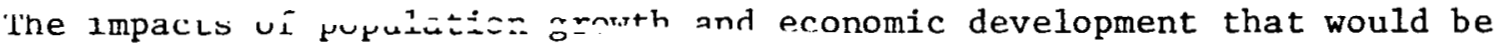
directly related to construction of a 5-GW rectenna are somewhat easier to estimate. As discussed in Sec. 3, once the size of the primary work force and the time required to construct an energy facility are known, secondary growth can be estimated using employment multipliers. By estimating the household size for primary, secondary and other workers; multiplying workers by household size; and summing the estimates of total population for each year, a profile of demographic change can be developed for the entire construction period. This export-base approach, which is identical to the principles used in SEAM, is best suited to the study of SPS rectenna construction for several

*Other Societal Assessment white papers by Blackburn (Rice University), Donalek and Wysong (Harza Engineering), and Kotkin (Economic Consultants) consider different rectenna siting patterns. However, since these papers were being prepared at the same time this paper was in preparation, it has been impossible to consider their implications here. 
reasons. First, Santini's findings, as indicated in the previous section, strongly support the use of export-base theory in projecting regional economic and demographic change. Second, actual sites have not been selected and, as explained in Sec. 3, demographic impact greatly depends on labor force availability which varies between regions. Use of an export-base approach could be used to show how demographic impact varies depending on alternative rectenna locations that might be selected. Third, regional shifts in energy production, total electric generating capacity (i.e., the availability of electricity) or other factors may well alter the spatial distribution of economic activity before SPS becomes operational. The export-base approach can deal with this uncertainty by employing different forecasts of future regional economics to gauge the range of demographic impacts from rectenna construction. Finally, and most important, since export-base modeling involves a straightforward multiplier approach, direct uses can be made of the rectenna siting work and construction labor force estimates that will be developed in other parts of the assessment process. In addition to these advantages, the exportbase approach as operationalized in SEAM provides a foundation for the study of local service impacts resulting from population change due to rectenna construction.

\subsubsection{Rectenna Operation}

Several factors will influence the attraction of industry when the 5-GW rectenna sites become operational. Section 2 reviewed the primary and secondary factors affecting industrial location. Those factors considered primary in business location included: energy availability and costs; transportation availability and costs; raw materials availability and cost; the cost, availability, and productivity of labor; and market factors. This section relates each of these factors to operation of the proposed SPS.

A critical question concerning energy availability is, again, the location of the rectenna sites. Industries located in certain areas of the country may not be able to obtain their electric power needs by the year 2000, at any cost. For example, the long-term electric power situation for aluminum production (an electric-intense process), is uncertain in the Pacific Northwest. Based on the projected supply and demand for electric power in the region, the Bonneville Power Administration announced in 1976 that it could not renew its power contracts with the aluminum industry after the 1984-88 period when the 
present contracts expire. ${ }^{6}$ Thus industries which are heavily dependent on electrical power for their productive capacity may relocate toward the rectenna sites.

Of key importance to industrial mobility spurred by energy is the price at which electricity is sold. There are several pricing strategies that can be applied to electrical energy. They include: average cost pricing, capacity-only pricing, peak and off-peak pricing, energy-only pricing, and marginal cost pricing. Average and marginal cost pricing are particularly important in considering industrial location incentives. In its simplest form, average cost pricing means that the price per kilowatt-hour ( $\mathrm{kWh}$ ) equals the total cost of generating the electricity divided by total output plus some predetermined fair rate of return. In terms of SPS, this would mean total annual operating costs plus design, development, test, and evaluation (DDT\&E) costs plus construction costs divided by output. The ECON report on SPS costs indicates that for the photovoltaic concept, average costs are $35 \mathrm{mills} / \mathrm{kWh} .^{7}$ Marginal costs, on the other hand, are only the costs which occur in operating the system (extra cost per $\mathrm{kWh}$ ). Hence, marginal cost pricing would set electric rates equal to marginal cost per kWh plus some fair rate of return. According to the ECON study, ${ }^{7}$ this results in an approximate price of $26.7 \mathrm{mills} / \mathrm{kWh}$ for the photovoltaic version of SPS. Thus, if marginal cost pricing is used, there would be a $24 \%$ decrease in electrical rates over

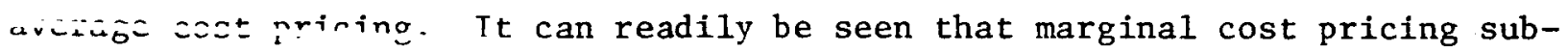
stantially lowers rates to the user and increases the likelihood that firms will relocate to the SPS rectenna-bearing regions.

The question of whether to price the outputs of regulated industries at marginal cost is not a new one. Hotelling ${ }^{8}$ and many other economists have explored the marginal cost pricing concept. Hotelling contends that marginal cost pricing results in a net benefit to society and others point out that marginal cost pricing would redistribute wealth. That is, development and construction costs must be paid by income taxes in order to provide the lower marginal cost price. Since income taxes are progressive, wealthier individuals would bear a greater burden of the development and construction costs while not receiving increased benefits through greater electrical consumption. The question of which pricing mechanism is used is central to industrial location and should be studied in depth. 
Another price-related issue is pricing to create a market for SPS power. Since the availability of SPS electricity will be virtually uninterrupted, there will be incentives to marginal price output in order to assure a full market or load factor. The question of peak and off-peak pricing policy is also important to industrial location. To this point, we have stressed industrial energy requirements, but U.S. balance of payments problems are transportation (i.e., oil) related. Transportation demand is very uniform throughout the year (if not the day). Electric cars could store SPS energy in off-peak hours at low marginal cost and then operate on it during the day. It may also be possible to use SPS electricity to create hydrogen from water for hydrogen-powered vehicles. These alternatives have the desirability of leveling average daily transportation energy demand which can be further smoothed out by pricing to encourage storage. Hydrogen could also be generated and stored in tanks, like other liquid or gaseous fuels, when no other demand existed. The fuel could be sold out at a later date and could be priced to sell when tanks are full in a manner analogous to present-day oil storage. This form of storage could smooth out seasonal effects. The possibility also exists for storing fuel for space-powered vehicles.

Another electrical-energy-related issue is the distribution of SPS electricity through the national power grid. Many different strategies could be employed to distribute the power. These include: competitive bids (thus eliminating the marginal cost-pricing possibility); first-come, first-serve, on the basis of regional economic development plans set forth by the federal government and many others. The distribution of SPS outputs is critical to the location of industry.

As noted earlier, transportation costs and availability are considered by many theorists as the key factors influencing industrial location. Some industries that incur high transportation costs in moving their product may not be induced to relocate to a rectenna site regardless of the price of energy. Conventional (open hearth or basic oxygen furnace) steel production would fall into this category and any bulky material industry is likely to be precluded from relocation to cheap energy. For example, while fuel and electrical costs are $50-55 \%$ of the total production costs for Portland cement, transportability of the product will be the prime determinant of manufacturers' location. 
Some industries must locate near sources of raw materials because of availability and cost considerations. One would not expect the mining industry to relocate toward a rectenna, although it may be expected that the smaller industries could move, depsite their dependence on raw materials. This possibility is likely for the Texas rectenna sites indicated in the study by A.D. Little, Inc. ${ }^{5}$ The reason for this is that seabed ferroalloy mining smelters could be sited in Texas ${ }^{10}$ and, hence, the availability of raw materials would work in harmony with the availability of SPS energy.

Labor cost, availability, and productivity factors may constrain many industries from relocating toward rectenna sites since many of the suggested sites are rural. For example, the machine tool industry may not relocate based on the availability and/or cost of energy since it depends on highly specialized labor which is not found in suggested rectenna regions.

Markets are also prime determinants of industrial location. Firms strong1y dependent on the maximization of profit and which locate in their market region probably will not relocate to sparsely populated rectenna-bearing regions.

Besides these primary factors, there are many secondary factors that affect industrial location. These factors include: topography, climate, and water availability, government policies (including subsidies, ownership, environmental laws and other legislation, and taxation), and personal considerations of

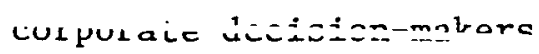

Government policies are the most important of these secondary factors. By direct legislative action or by indirect pricing policies, the government can exert significant influence over industrial locations around the SPS rectennae. As mentioned above, the pricing policies that are established for SPS power will exert significant incentive or disincentive for relocation. The effect of these policies on industrial mobility should be explored in future work.

\subsubsection{Location Options Available to Firms}

Location options that facilitate industrial consumption of SPS generated electricity are somewhat limited. Present safety standards require the microwave beam to be diffused for Earth reception. The rectenna sites will therefore cover large areas of land, located away from population concentrations 
and, the outputs will either have to be transmitted back to urban/industrial load centers or a significant proportion of the load will have to relocate to areas within which SPS outputs can be transmitted economically.

As discussed in the previous section, the availability and cost of electricity are primary factors that will influence electrically intense industries to move toward rectenna sites. However, in lieu of relocation, firms may consider a range of options depending upon the availability and price of SPS electricity relative to other forms of electricity generation. Firms may decide to stay in their present locations and reduce their electric demand by lowering production, altering their manufacturing process(es) or diversifying their product line. Some firms may decide against relocation and develop their own generating facilities to supply a growing demand for electricity. Alternatively, firms may choose from a set of options mid-range between relocating and staying in their present locations. These mid-range options would include decisions to relocate only new facilities, relocation of electrically-intense processes with shipment of component products to assembly plants or, the payment of premium utility rates to cover the cost of transmission, thereby eliminating the need to move toward a rectenna site.

Future research dealing with the economic and demographic implications of SPS should examine the industry-specific sensitivity of firm mobility to the future availability and cost of electricity. An understanding of this sensitivity is critical to estimating movements of population (i.e., 1abor and dependents) that can be expected to follow.

\subsubsection{Government Options to Stimulate Utilization of SPS Outputs}

Business decisions are, to a large extent, influenced by government policies and it may be necessary for the federal government to develop incentives that initially stimulate the market for SPS outputs. Such inducements may include tax incentives, federal loan guarantees for new facilities developed within rectenna service areas, relocation subsidies or, grants-in-aid to industrial consortia that would relocate electrically-dependent and interrelated processes. As indicated above, current law and the existing U.S. political structure militate against policies that would provide economic advantages for the development of new areas at the expense of degenerating existing centers of economic activity. Again, we emphasize that any federal incentives to stimulate the use of SPS outputs must be carefully examined before they can be suggested for policy. 
Although it is unlikely that SPS would provide additional generating capacity significantly in excess of long-run demand,* government incentives may be needed to stimulate initial relocations of industry. Deployment of such incentives could serve as catalysts to redistribute population and benefit long range national and regional development goals. Future research should therefore assess the sensitivity of industrial moves to government incentives that might effect the utilization of SPS outputs. It should also be mentioned that government policies and incentives could be applied to retard or direct growth that either exceeds the generating capacity added by SPS or outstrips the impact assimilating capacity of the region. The research on industrial moves and government incentives should also consider what public policies could be applied with what effect to restrain unwanted growth.

\subsection{PUBLIC ACCEPTANCE}

Many factors will influence public opinion about SPS. Prominent among these factors are: (1) the availability of electricity in the 21st century, (2) the cost of an operational system and its effect on taxes and/or electric utility rates, (3) the price of alternative fuels, (4) the vulnerability of the system to sabotage, (5) the technological state of society, and (6) the world political situation. These and the many other issues affecting public acceptance are indeed complex and they are addressed more fully in other Jucicial Aszacamont white papers.** As a complement to these discussions, this section has a more narrow focus. Here we shall concentrale va tha ?fforts that rectenna siting may have on public acceptance of industrial and population relocation. The major implications examined, albeit briefly, are: (1) displacement of population from large areas of land for rectenna sites, (2) potential "boom" development of rectenna construction communities, and (3) the geographic concentration of economy and society in rectenna-bearing regions.

\footnotetext{
*NASA estimates that SPS could be providing $20 \%$ of total U.S. electrical capacity by $2025 .^{1}$

**See Public Acceptance of the Satellite Power System by A. Bachrach (Environmental Resources Group) and Impact of Centralization/Decentralization on a SatelZite Power System by J. Naisbitt (Center for Policy Process).
} 


\subsubsection{Displacement of Population from Rectenna Sites}

As indicated earlier, the U.S. standards for human exposure to microwave radiation dictates that the $5-$ GW SPS rectenna sites will consume large amounts of land and hence they will probably be located in undeveloped regions on relatively cheap land. Nevertheless, there are important implications for the displacement of population and the conversion of existing economic activity that must be considered. As an example of the level of population displacement impact that might be expected, a rough calculation was made using sites approximated from a preliminary study by Arthur D. Little, Inc. ${ }^{5}$ Using 1970 population data for counties estimated as locations for each of the four sites in western South Dakota and the four sites in southeastern Nevada, it was estimated that rough1y 1800 persons would need to be relocated if rectenna construction were to begin immediately.*

Given the crude assumptions employed in this calculation, it is more realistic to estimate that the total population displaced among these sites would range between 1050-2000 persons.** While this is not a large number relative to the 40-GW equivalent of electric generating capacity that would be developed, public opinion may be more influenced by the displacement of economic activity than by the displacement of population in extremely rural areas such as these. For example, how will the contributions made by these counties to the state or regional economies be affected by the rectenna site? Regardless of whether economic displacement would, in this case, be greater in South Dakota than in Nevada or vice versa, displacements of the prevailing economic activity will undoubtedly affect public acceptance of rectenna sites in general

*For the purposes of this calculation, the following counties were used as proxies for sites shown in a briefing document furnished 21 June 1978 by Arthur D. Little, Inc.: Nevada--Lincoln (2 sites), Nye and Clark Counties; South Dakota--Pennington (2 sites), Haakon and Jackson Counties. After subtracting the areas and populations for Las Vegas from Clark County, Nevada and Rapid City from Pennington County, South Dakota, the nonurban population was assumed to be uniformly distributed over each county. The number of persons displaced by an elliptical rectenna requiring $132 \mathrm{~km}^{2}\left(\simeq 51.0 \mathrm{mi}^{2}\right)$ was then calculated.

**This range is approximately two standard deviations on either side of the mean number of persons displaced by the eight sites in the six county areas considered. Since this estimate is based on 1970 data, we feel it is conservative and that it may substantially underestimate the actual level of population displacement that would result in the early part of the next century. 
and these economic impacts will be particularly crucial to the public acceptance of SPS in rural areas.

By contrast, the displacement of population will be potentially more important in the formulation of public opinion about rectenna sites in the more metropolitan regions such as those indicated for Wisconsin, Iowa, Missouri and northern California. This is because relatively greater numbers of people would be displaced and there would be a potentially larger base of opposition. Related to this issue of population displacement in more urban regions is the disruption of local service economies which may have to be relocated to the periphery of proposed rectenna sites. This disruption of economic activity is intimately related to population displacements and both factors will affect public acceptance of rectenna sites in urbanized regions.

\subsubsection{Boom Development from Rectenna Construction}

Much has already been written about the impacts of rapid growth from energy boom developments ${ }^{1-15}$ and much of the understanding about these problems can be extrapolated to the construction of SPS rectenna facilities. Since each rectenna would contain on the order of $10^{10}$ dipole receiving elements $^{16}$ that would have to be assembled, anchored and connected electronically, a large construction force will probably be needed at each site in order to achieve the schedule envisioned for implementing two 5-GW systems per year. The economic, demograpnic aud suciz=:-1+vral consequences of this activity will affect public acceptance of rectenna sites. Furthermore, opinions formed on the basis of experience with these construction impacts can be expected to flow over into public acceptance of the entire SPS concept.

In order to understand the intensity of public reaction to rectenna construction, it is first necessary to determine the size of the primary construction force and the time required for completion of a project. This information can be used to estimate the intensity of the construction impact at any given site using the SFAM methodology described in Sec. 3. Based on these estimates, preliminary assessments can be made of the public acceptance of SPS. 


\subsubsection{The Centralization of Society}

Public acceptance may also be influenced by the effect that SPS has on the centralization of society. One of the other Societal Assessment white papers addresses the centralization issue as it has been broadly discussed with reference to large electric generating systems.* This discussion complements that treatment of the more traditional centralization issues, but consideration here is limited to the geographic concentration of economic activity and population.

At this preliminary stage, it would appear to these writers that SPS will not revolutionize society to a more centralized state. Nor do we presently feel that SPS will even hasten the centralization of economic activity in the U.S. In fact, the opposite effect may be a more realistic expectation. Given the need to locate rectenna sites in rural areas, SPS may serve as a catalyst to decentralize the U.S. economy and society from its present state.

SPS may have a decentralizing effect on American society for two reasons. First, the greatest impetus to move to rectenna-bearing regions would be among electricity-dependent industries which tend to be more capital intensive than they are labor intensive. Although there would be some immediate shift of investment from existing urban/industrial centers to newly developing regions containing rectenna sites, the shift of jobs and population would be slower to evolve and the existing spatial distribution of society would remain largely unchanged. If this is an accurate picture of what may happen, SPS may be credited as exerting more of a decentralizing than centralizing force on American society. Second, by the time that SPS becomes operational, the economics of transmitting electricity may change to the extent that power can be shipped long distances back to existing urban/industrial load centers. If this becomes the case, any movements to rural rectenna-bearing regions would be counter to the trend of centralization that would continue if SPS electricity were to be transnitted to existing loads.

\footnotetext{
*The white paper entitled Impact of Centralization/Decentralization on a Satellite Power System by J. Naisbitt deals with the more fundamental centralization issues surrounding large electric generating systems such as nuclear power. That discussion includes consideration of government involvement in system development and regulation, the concentration of decisionmaking in the electric utilities and financial institutions, and the influence of public involvement in electric system planning.
} 
Regardless of whether SPS exerts a centralizing or decentralizing force on American society, public opinion about rectennae siting will undoubtedly be affected by perceptions of spatial redistributions in economic activity. However, before this aspect of the siting issue can be considered, it is first necessary to examine how the distribution of economic activity and society may be affected by SPS. Public acceptance of these consequences should be a topic for later investigation.

\subsection{INTERNATIONAL MOBILITY}

At this stage it is virtually impossible to anticipate what consequences the siting of SPS rectenna might have for international relocations of economic activity and population. Like the issue of public opinion about domestic relocations, this one must also await the development of information about rectenna siting. But in addition, the study of international relocations must also await further definition of the SPS concept, the development of foreign affairs and evolution of the world economy. All of these will require the passage of time. Since international relocation is clearly a topic that will gain importance as the evaluation of SPS proceeds, it would be best to wait until the initial assessments of domestic relocation impacts are available. This understanding can then be applied to the international realm.

There are, however, several questions that need to be answered in the short term to provide the building blocks for lucule aszaczmonta of international moves that may occur subsequent to rectenna siting. What is the prospect that rectennae would be sited outside the U.S. and in what countries or regions of the world might they be located? How might the future availability and cost of electricity affect international movements of industry by the time SPS become operational? How might the world economic situation (i.e., U.S. balance of payments, foreign money markets, corporate investment strategies, etc.) influence industrial attractions to rectenna sites and/or decisions to invest in SPS? These are complex questions and they are beyond the scope of initial assessments that are needed on economic/demographic relocations. However, they should be considered in the international portion of the initial societal assessment effort. 


\subsection{OTHER PROBLEMS AND IMPLICATIONS}

In addition to the issues discussed thus far, SPS may also affect other movements of industry and population. These other effects would include relocations caused by expansions of (1) the aerospace and solar technology industries, (2) other industries contributing to SPS deployment and, siting of the Heavy Launch Vehicle (HLV) facility. While "spin-off" impacts such as these could be expected from any large-scale program, they may be especially important in an effort as large as SPS. Implementation of the present concept would cause sizeable shifts of the nation's manpower in terms of both occupational structure and spatial location. These shifts could have important consequences for the metropolitan areas of Boston, Houston, Los Angeles, Miami, Seattle and other centers of aerospace activity. The primary stimulus of SPS jobs, combined with attractions of related export-base industries and secondary economic activity, would generate growth and socioeconomic impact.

Since these relocation effects must be planned for in the future, they should be examined as part of the societal assessment. However, we would emphasize that these relocations are substantially easier to assess than the effects that rectennae siting may have on industrial and population relocations since precedent exists for assessing aerospace impact. Since it is more difficult to assess the economic and demographic impacts of rectennae siting, it is also necessary to initiate research on this subject early in order to develop the complete analysis which is essential. The "critical path" requires starting on the more difficult part of the needed research first. 
1. NASA, George C. Marshall Space Flight Center, Satelzite Power System Engineering and Economic Analysis--Sumamy, NASA TM X-73344

(Nov. 15, 1976).

2. Solar Power Satellite Baseline Review by MSFC-JSC, Preliminary (July 13, 1978).

3. U.S. Bureau of the Census, Statistical Abstract of the United States, 1976.

4. Eberhardt, Anne W., Candidate Locations for SPS Rectifying Antennas, NASA TM-78146 (Nov. 1977).

5. Arthur D. Little, Inc., Rectenna Siting Requirements, unpublished information.

6. Stamper, John W., and Horace F. Kurtz, Mineral Commodity Profizes: Aluminum, Bureau of Mines Report MCP-14, Washington, D.C. (May 1978).

7. Bloomquist, Charles E., A Survey of SateZZite Power Stations, PRC Systems Science Co. report PRC R-1844 (Sept. 1976).

8. Hotelling, Harold, The General Welfare in Relation to Problems of Taxation and of Railway and Utility Rates, Econometrica, 6:242-69 (1938).

9. Miller, E. Willard, Manufacturing: A Study of Industrial Location, Pennsylvania State University Press, University Park, PA (1977).

10. Lawson, Herbert G., Sea-Bed Slowdown, Wa11 Street Journa1 (July 31, 1978).

11. Baldwin, T.E., E. Dixon-Davis, E.M. Stenehjem and T.D. Wolsko, A Socioeconomic Assessment of Energy Development in a Smalz Rural County: Coal Gasification in Mercer County, N. Dakota, Argonne Nationa1 Laboratory Report ANL/AA-5 (Aug. 1976).

12. Baldwin, T.E., and R. Poetsch, An Approach to Assessing Sociocultural Impacts Using Projections of Population Growth and Composition, Argonne National Laboratory Report ANL/EES-TM-24 (Aug. 1977).

13. Gilmore, John S., Boom Towns May Hinder Energy DeveZopment, Science, pp. 535-540 (Feb. 13, 1976).

14. Mountain West Research, Inc., Construction Worker Profize: A Study for the old West Regional Commission, old West Regional Commission (Dec. 1975).

15. Stenehjem, E.J., Forecasting the Local Economic Impacts of Energy Resource Development: A Methodological Approach, Argonne National Laboratory, ANL/AA-3 (Dec. 1975).

16. Bloomquist, Charles E., A Survey of Satelzite Power Stations, PRC Systems Sciences Co., PRC R-1844 (Sept. 1976). 


\section{FUTURE RESEARCH NEEDS}

Future research needs can be divided into initial short-term assessments and long-term research. Short-term assessments are first needed to build an arsenal of tools and understanding that can serve as a foundation for the more refined assessments that will be needed later as evaluation of the SPS concept proceeds. Long-term research should be aimed at developing accurate predictions of the future economic and demographic relocations that may result from the siting of SPS rectennae.

\subsection{SHORT-TERM}

Before investigators can seriously tackle the larger question of how SPS will contribute to the centralization or decentralization of society, a foundation of tools and information is needed to build upon. The shortterm assessments identified in this section are recommended as efforts that should be supported in FY 1979 as prerequisites to the more detailed studies that will be needed in FY 1980 and beyond. These assessments focus on four of the most important economic/demographic issues that have been raised in this white paper. All of these assessments relate to the fundamental question of rectenna siting and they would specifically focus on four concerns: the maximization of economic and demographic benefit, the relationship between electricity prices and industrial moves, potential socioeconomic impact, and the future locational responsiveness of industry based on the projected availability and cost of electricity. These short-term assessments can be summarized more fully as follows:

- Rectenna siting assessment (two possible approaches)

- Search for sites (i.e., counties) to maximize economic/demographic benefits.

- Evaluate the economic/demographic viability of sites identified by others.

- Assess the expected effects of marginal and average cost pricing on industrial moves to rectenna-bearing regions. This assessment would include some sensitivity analysis.

- Ex ante assessment of economic/demographic impact of rectenna siting. This assessment would examine the following phases of development: 
- Rectenna construction and secondary growth.

- Initial industrial relocation and secondary growth.

- Attraction of related industrial economic activity and their secondary effects.

- Assess the responsiveness of industry to relocate facilities based on the availability and cost of electric power. This assessment would include:

- Identification of electric intensive industries and processes.

- Consideration of projected regional generating capacities that may influence future shifts in the spatial location of industry.

- Price comparisons of SPS electricity with other forms of generation.

- Identification of industry-specific resource needs and other incentives that may influence relocation decisions such as water availability; transportation or labor requirements; market locations; and government policies at the local, state and federal levels.

Assess the legal and political implications of government incentives that may be considered to stimulate the use of SPS outputs through encouraging industrial relocations. This assessment would include:

- Identification and review of laws governing the economic development of new areas.

- Consideration of issues identified in other Societal Assessment white papers that would affect the implementation of government incentives (e.g., finance/management, public acceptance, and centralization/decentralization).

- Consideration of the impact that the implementation of such incentives may have on existing policy goals (e.g., urban redevelopment).

These short-term assessments will require information about the industrial markets that SPS can be expected to serve. Anticipation of these markets is essential to the development of economic and population projections using the export-base approach advocated in earlier portions of this paper. It should not be inferred that the concern for markets implies either advocacy for or a promotional view toward SPS. 


\subsection{LONG-TERM}

Based on the tools and understanding developed in the short-term assessments, long-term research should examine the question of whether SPS deployment will contribute to the centralization or decentralization of economic activity and society. Resolution of this issue and the ability to accurately predict the future sociodemographic consequences of SPS will require basic research on the following topics in FY 1980 and beyond:

- Radial effects of industrial location as consequences of future electric transmission efficiency and the cost of SPS energy to the user.

- The proportion and composition of economic activity that can be expected to relocate subsequent to rectenna siting.

- The economic and demographic consequences of redistributing capital investments due to SPS deployment.

- How public opinion about rectenna siting and attendant sociodemographic impacts may affect any of the above.

- International movements of economic activity and population that may be affected by rectenna siting. 


\section{BIBLIOGRAPHY}

Asbury, Joseph G., and Ronald 0. Mueller, Solar Energy and Electric Utilities: Should They Be Interfaced?, Science, 195:445-450 (Feb. 1977).

Arianin, A., and S. Nikolaev, Interregional and Intraregional Analysis of the Location of Productive Forces, Regional Science Association Papers and Proceedings, 24:163-170.

Baldwin, Thomas E., and Roberta Poetsch, An Approach to Assessing Local Sociocultural Impacts Using Projections of Population Growth and Composition, Argonne National Laboratory Report ANL/EES-TM-24 (Aug. 1977).

Battelle/Pacific Northwest Laboratories, Systems Methodology for Assessing the Demographic Implications of Energy Development, Battelle report BNWL-2084RAP-6-UC-11 (Sept. 1976).

Birch, David L., et al., A Model of Population and Employment Change for Metropolitan and Rural Areas in the United States, Massachusetts Institute of Technology, Cambridge, Massachusetts (March 1978).

Blanco, Cicely, The Determinants of Interstate Population Movements, Journal of Regional Science, pp. 77-84 (Summer 1963).

Bloomquist, Charles E., A Survey of SatelZite Power Stations, PRC System Sciences Company report PRC (Sept. 1976).

Bodenhofer, Hans-Joachin, The Mobility of Labor and the Theory of Human Capital, The Journal of Human Resources, II:431-448 (Fal1 1967).

Borts, George H., and Jerome L. Stein, Economic Growth in a Free Market, Columbia University Press, New York, New York (1964).

Chenery, Hollis B., Interindustry Economics, John Wiley and Sons, Inc., New York, New York (1959).

Day, Dawn, and Dorothy K. Newman, The American Energy Consumer, Ballinger Publishing Company, Cambridge, Massachusetts (1975).

Eberhardt, Anne W., Candidate Locations for SPS Rectifying Antennae, Marshall Space F1ight Center Report NASA-TM-78146 (June 1971).

Emerson, M. Jarvin, and F. Charles Lamphear, Urban and Regional Economics: Structure and Change, Allen and Bacon, Boston, Massachusetts (1975).

Frigerio, N.A., et al., Site: A Methodology for Assessment of Energy Facility Siting Patterns, Argonne National Laboratory Report ANL/AA-2 (Aug. 1975).

Foster Associates, Inc., Electric Rate Concepts and Structures, Foster Associates Report (May 1976).

Gallaway, LowellE., Industry Variations in Geographic Labor Mobility Pattems, The Journal of Human Resources, II:461-474 (Fall 1967). 


\section{Bibliography (Cont'd)}

Gallaway, Lowel1 E., et al., The Economics of Labor Mobility: An Empirical Analysis, Western Economic Journa1, V(3):211-223 (June 1967).

Gilmore, John S., and Mary K. Duff, The Sweetwater County Boom: A Challenge to Growth Management, University of Denver Research Institute, Denver, Colorado (July 1974).

Greenwood, Michael J., The Economics of Labor Mobility: An Empirical Analysis: Comment, Western Economic Journal, VI(3):243-244 (June 1968).

Greenwood, Michae1 J., Research on Intermal Migration in the United States: A Sumey, The Journal of Economic Literature, 13(2):397-433 (June 1975).

Guyol, N.B., The World Electric Power Industry, University of California Press, Berkeley, California (1969).

Hermelee, Alan L., Regional Reference Energy Systems, Brookhaven National Laboratory Report EPRI-EA-462 (June 1977).

Hotelling, Harold, The General Welfare in Relation to Problems of Taxation and of Railway and Utility Rates, Econometrica, 6:242-269 (1938).

Hummon, N. and D. Sharp, Nationwide Personal Transportation Sumey, U.S. Department of Transportation FHWA (1970).

Isard, Walter and J.H. Chamberland, New England as a Possible Location for an Integrated Iron and Steel Works, Economic Geography 26: 245-259 (1950).

Isard, Walter, et al., Regional Economic Impacts of Nuclear Power Plants, Brookhaven National Laboratory Report BNL-50562 (Aug. 1976).

Isard, Walter, Location and Space-Economy, The M.I.T. Press, Cambridge, Massachusetts (1956).

Keeney, Ralph L., and Keshavan Nair, Decision Analysis for the Siting of Nuclear Power Plants -- The Relevance of Multiattribute Utility Theory, M.I.T. Operations Research Center Report MIT OSP 73787 (June 1974).

Little, Arthur D., Inc., Rectenna Siting Requirements, unpublished information.

Lowry, Ira S., Migration and Metropolitan Growth: Two Analytical Models, Chandler Publishing Co., San Francisco, California (1966).

Lowry, Ira S., A Model of Metropolis, Memorandum RM-4035-RC. The Rand Corporation, Santa Monica, California (1964).

Kurtz, Horace F., and John W. Stamper, AZuminum, U.S. Bureau of Mines Mineral Commodity Profiles MCP-14 (May 1978).

Marshall Space Flight Center, Solar Power Satellite Baseline Review, unpublished information (July 1978). 
Mazek, Warren, The Efficacy of Labor Migration with Special Emphasis on Depressed Areas, Working Paper CUR-2, Institute for Urban and Regional Studies (June 1966).

Miernyk, William H., Some Regional Impacts of the Rising Costs of Energy, Regional Science Association Papers and Proceedings, 37:213-227 (Nov. 1975).

Miernyk, William H., The Elements of Input-Output Analysis, Random House, New York, New York (1967).

Miernyk, William H., et al., Regional Impacts of Rising Energy Prices, Ballinger Publishing Company, Cambridge, Massachusetts (1977).

Miller, Willard E., Manufacturing: A Study of Industrial Location, The Pennsylvania State University Press, University Park, Pennsylvania (1977).

Morrison, Peter, et al., Overview of Population Forecasting for Small Areas, Rand Corporation Report AD-A022-244 (June 1975).

Muth, Richard F., Migration: Chicken or Egg?, The Southern Economic Journal, pp. 295-306 (Jan. 1971).

Myers, George C., Migration and the Labor Force, Monthly Labor Review, :12-16 (Sept. 1974).

Myers, John G., Energy Consumption in Manufacturing, Ballinger Publishing Company, Cambridge, Massachusetts (1974).

National Aeronautics and Space Administration, Satellite Power System (SPS) Concept Deveiopmient and Evaluation Program PLan, NASA Report DOE/ET-0034 (Feb. 1978).

National Aeronautics and Space Administration, Satellite Power System: Engineering and Economic Analysis, NASA Report TM-X-73344 (Nov. 1976).

Nelson, R., Marginal Cost Pricing in Practice, Prentice-Ha11, Inc., Englewood C1iffs, New Jersey (1964).

Planning and Conservation Foundation, The Marginal Cost and Pricing of Electricity: An Applied Approach, Planning and Conservation Foundation Report PB-255-967 (June 1976).

Planning Research Corporation, Statement of Work: Preparation of a White Paper on the Impact of a Satelizte Power System (SPS) on Relocation, Draft PRC Report (May 1978).

PRC Energy Analysis Company, Interim Environmental Guidelines for Satellite Power System (SPS) Concept Development and Evaluation, PRC Report (June 1978).

Policy Research Associates, Socioeconomic Impacts: Nuclear Power Station Siting, U.S. Nuclear Regulatory Commission Report NUREG-0150 (June 1977). 


\section{Bibliography (Cont'd)}

Real Estate Research Program, Industrial Location Bibliography, University of California at Los Angeles (July 1959).

Rice, P.L., and D.P. Vogt, Energy Avaizabilities for State and Local Development: A Methodological and Data Overview, Oak Ridge National Laboratory Report ORNL/ TM-5890 (June 1977).

Richardson, Harry, Regional Economics: Location Theory - Urban Stmucture Regional Change, Praeger Books, New York, New York (1969).

Santini, Danilo J., An Econometric Model of Transportation Infrastructure as a Determinant of Intraurban Location, Journal of Regional Science, 18(1) (1978).

Santini, Danilo J., The General Property Tax Examined in a Suburban Cook County Context, Master's Thesis, Illinois Institute of Technology (1972).

Santini, Danilo J., Urban Acquisition and AZZocation of Human Resources: Two Integrated Econometric Models Accounting for Urban Function, Ph.D. Dissertation, Northwestern University (1976).

Shields, Mark A., Social Impact Assessment: An Analytic Bibliography, Brown University paper 74-P6 (Oct. 1974).

Smith, David M. Industrial Location: An Economic Geographical Analysis, John Wiley and Sons, Inc., New York, New York (1971).

Spanger, Uwe, and Peter Treuner, Statistical Analysis of Location Determinants, Regional Science Association Papers and Proceedings, 35:143-156 (Nov. 1975).

Stenehjem, Erik J., Forecasting the Local Economic Impacts of Energy Resource Development: A Methodological Approach, Argonne National Laboratory Report ANL/AA-3 (Dec. 1975).

Stevens, Benjamin H., and Carolyn A. Brackett, Industrial Location: A Review and Annotated Bibliography of Theoretical, Empirical, and Case Studies, Regional Science Research Institute, Philadelphia, Pennsylvania (1974).

United Nations Industrial Development Organization, Industrial Location and Regional Development, United Nations Publication, New York, New York (1971).

U.S. Bureau of the Census, Annual Sumey of Manufacturers: 1973 Statistics for States, SMSAs, Large Industrial Counties, and Selected Cities, Government Printing office, Washington, D.C. (1976).

U.S. Bureau of the Census, Federal-State Cooperative Program for Population Estimates, Current Population Reports, Series P-26, Government Printing Office, Washington, D.C. (1977).

U.S. Bureau of the Census, Mobility of the Population of the United States, March 1970 to March 1975, Current Population Reports, Population Characteristics, Series P-20, Government Printing Office, Washington, D.C. (1975).

U.S. Bureau of the Census, Statistical Abstract of the United States: 1977, 98th Edition, Government Printing Office, Washington, D.C. (1977). 


\section{ACKNOWLEDGMENTS}

Appreciation is expressed to all who fostered this white paper. Special appreciation is extended to Thomas D. Wolsko, Charles E. Bloomquist, Sung-Woong Hong, Patricia W. Mosena, and June F. Johansen. To all of these, and to others not mentioned, we extend a grateful "thank you" for your assistance. 